\title{
Ultrasonography of the Mediastinum: Techniques, Current Practice, and Future Directions
}

\author{
Leonello Fuso MD, Francesco Varone MD, Daniele Magnini MD, Mariarosaria Calvello MD, \\ Erminia Lo Greco MD, and Luca Richeldi MD PhD
}

\author{
Introduction \\ Technical Aspects and Equipment \\ Equipment \\ Needles \\ Technique \\ Echographic Morphology of Mediastinal Lymph Nodes \\ Suction Versus Non-Suction \\ Adequacy Criteria for EBUS Specimens \\ Ultrasound Techniques in the Diagnosis and Staging of Lung Cancer \\ Mediastinoscopy Versus Endosonography \\ EBUS-TBNA and Endoscopic Ultrasound-Fine Needle Aspiration \\ EBUS-TBNA and Endoscopic Ultrasound With Bronchoscope-Fine \\ Needle Aspiration \\ Cytology and Ancillary Testing \\ Ultrasound Techniques in the Diagnosis of Lymphoma \\ Diagnostic Approach \\ Specimen Handling \\ Perspectives \\ Ultrasound Techniques in the Diagnosis of Sarcoidosis \\ Ultrasound Techniques in the Diagnosis of Infections \\ Complications \\ Future Directions \\ Elastography \\ Confocal Laser Endomicroscopy \\ Therapeutic Use of Endosonography \\ Conclusions
}

\begin{abstract}
In the everyday practice of respiratory physicians, ultrasound techniques play a key role by enabling several diagnostic and interventional procedures. The application of ultrasound to endoscopic procedures allows both a visualization and a guided sampling of mediastinal and hilar lymph nodes. Endobronchial ultrasound can be combined with transbronchial needle aspiration, and, similarly, endoscopic ultrasound can be combined with fine-needle aspiration to sample virtually all mediastinal nodal stations from the airways and the esophagus. Endobronchial ultrasound-transbronchial needle aspiration and endoscopic ultrasound-fine needle aspiration showed a complementary diagnostic yield, and, recently, endoscopic ultrasound with bronchoscope was introduced in clinical practice to perform a transesophageal needle aspiration by using an ultrasound bronchoscope. This technique allows a single operator to perform both transbronchial and transesophageal needle sampling with the same instrument during a single bronchoscopic procedure. Mediastinal staging impacts the management of patients affected by lung cancer, and the most recent
\end{abstract}




\begin{abstract}
guidelines clearly state that endobronchial ultrasound and endoscopic ultrasound should be the initial tissue sampling procedure over surgical staging. In addition, endoscopic ultrasound techniques demonstrated an excellent yield in diagnosing lymphoma and benign diseases, for example, sarcoidosis. The aim of this review was to discuss the current role and future perspectives of endosonography techniques available for the evaluation of the mediastinum. Special emphasis was placed on equipment and technical aspects, the diagnostic role, and future directions of development. Key words: endosonography; EBUS-TBNA; EUS-FNA; mediastinal lymph nodes; lung cancer staging; lymphoma; sarcoidosis; EBUS needle injection therapy; simulator-based training. [Respir Care 2018;63(11):1421-1438. ㅇ 2018 Daedalus Enterprises]
\end{abstract}

\section{Introduction}

During the past decade, ultrasound-derived techniques have been introduced in the evaluation of mediastinal diseases. Ultrasound has conferred 2 main advantages: it is now able to be incorporated into endoscopes and allows real-time sampling of mediastinal lesions for diagnostic and, in case of malignancy, staging purposes. Both endobronchial ultrasound (EBUS) and endoscopic ultrasound are performed through an ultrasound probe directly applied to a bronchoscope and an endoscope, respectively. ${ }^{1}$ A convex-probe EBUS scope was introduced in 2004 to visualize mediastinal lymph nodes. ${ }^{2}$ However, the technique was already described 1 y earlier by Krasnik et al. ${ }^{3}$ The convex-probe-EBUS scope was developed to perform real-time transbronchial needle aspiration (TBNA) of the mediastinal and hilar lymph nodes under direct EBUS guidance (Fig. 1). Similarly, endoscopic ultrasound can be combined with fine needle aspiration, which allows a guided sampling of mediastinal lesions. EBUS-TBNA and endoscopic ultrasound-fine needle aspiration are considered minimally invasive procedures to obtain cytology or histology samples, hence, they have replaced surgical staging as a first step in the evaluation of the mediastinum of patients with suspected lung cancer., 4,5

Convex-probe-EBUS allows access to upper paratracheal (stations $2 \mathrm{R}$ and $2 \mathrm{~L}$ ), lower paratracheal (stations $4 \mathrm{R}$ and $4 \mathrm{~L}$ ), subcarinal (station 7), hilar (sta-

Drs Fuso, Varone, Magnini, Calvello, Lo Greco, and Richeldi are affiliated with Unità Operativa Complessa di Pneumologia, Fondazione Policlinico A Gemelli IRCCS Roma, Università Cattolica del Sacro Cuore, Italy. Drs Fuso, Varone, and Magnini are affiliated with Unità Operativa Semplice di Endoscopia Bronchiale Fondazione Policlinico A Gemelli IRCCS Roma, Università Cattolica del Sacro Cuore, Italy.

The authors have disclosed no conflicts of interest.

Correspondence: Daniele Magnini MD, Unità Operativa Complessa di Pneumologia, Fondazione Policlinico A Gemelli IRCCS Roma, Università Cattolica del Sacro Cuore, Largo Agostino Gemelli 8, 00168, Roma, Italy. E-mail: daniele.magnini@ hotmail.it.

DOI: $10.4187 /$ respcare. 06047 tions $10 \mathrm{R}$ and $10 \mathrm{~L}$ ), and interlobar (stations $11 \mathrm{R}$ and $11 \mathrm{~L}$ ) lymph nodes. ${ }^{5}$ Endoscopic ultrasound-fine needle aspiration is complementary to EBUS-TBNA by providing access to stations $2 \mathrm{~L}, 4 \mathrm{~L}, 7$, paraesophageal (station 8), and pulmonary ligament (station 9) lymph nodes (Fig. 2). ${ }^{5}$ Stations $2 \mathrm{R}$ and $4 \mathrm{R}$ are difficult to reach through the esophagus because of the interposition of the trachea; however, visualization and subsequent sampling is possible in selected cases of large lymph nodes $(>2 \mathrm{~cm})$. Stations 5 and 6 are often displayed by endoscopic ultrasound but can rarely be sampled without piercing the pulmonary artery or the aorta. ${ }^{5}$ Endoscopic ultrasound-fine needle aspiration can also reach the left adrenal gland, left lobe of the liver, and the celiac axis, which are potential sites of metastasis from lung cancer. ${ }^{5}$ Thus, the endoscopist gains a higher diagnostic accuracy by combining the 2 techniques into a single procedure rather than choosing one or the other. ${ }^{6,7}$ Over the past few years, a complete investigation of the mediastinum and the left adrenal gland has been performed during a single-scope procedure by a single operator who introduces the EBUS scope into the esophagus (endoscopic ultrasound with bronchoscope) after an EBUS procedure. ${ }^{8}$ The purpose of this review was to summarize the current practice, recent advances, and future directions of endoscopic ultrasound techniques in the evaluation of the mediastinum.

\section{Technical Aspects and Equipment}

\section{Equipment}

EBUS and endoscopic ultrasound are performed by using convex probes that are currently produced by 3 leading companies: Olympus, Tokyo, Japan; Pentax, Tokyo, Japan and Fujifilm, Tokyo, Japan. A variety of flexible endoscopes with different properties are commercially available (Table 1). The probe, which is integrated at the tip of the scope, scans parallel to the insertion direction of the instrument. Probes emit a range of frequencies between 5 and $12 \mathrm{MHz}$, which provides high-definition images at a depth of penetration up to $10 \mathrm{~cm}$. These instruments de- 


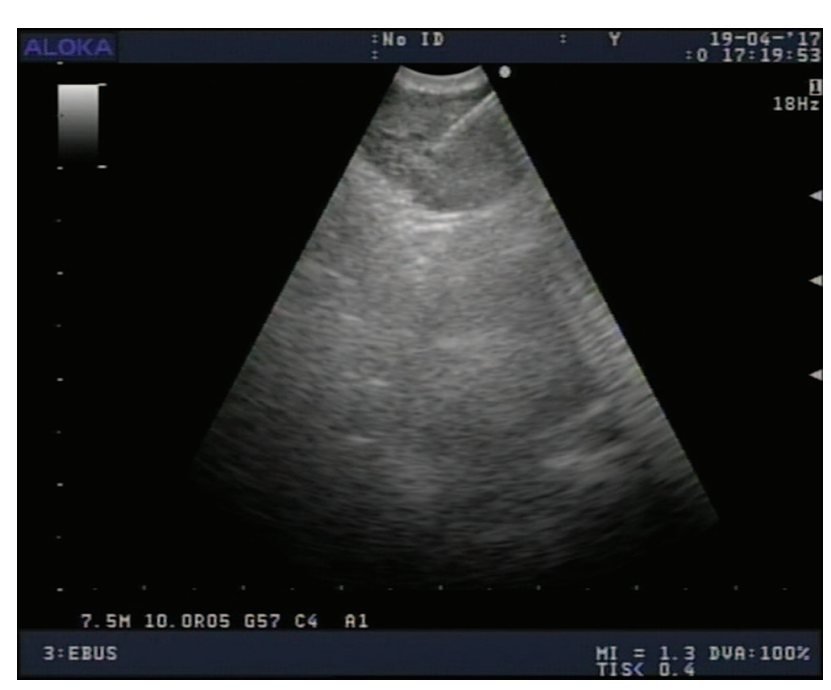

Fig. 1. Real-time transbronchial needle aspiration of a mediastinal lymph node.

liver an endoscopic and ultrasound image simultaneously and allow a real-time fine needle aspiration-TBNA of the visualized lesions. EBUS-TBNA and endoscopic ultrasound with bronchoscope-fine needle aspiration are performed with a dedicated needle, described in detail below. For a better coupling between the ultrasound probe and the airway wall, a balloon at the distal end of the bronchoscope could be inflated with sterile water. Moreover, the ultrasound probe is provided with the B-mode and power color-Doppler function, which improve the capacity of differentiating lymph nodes from vascular structures. ${ }^{1,9}$

\section{Needles}

Endoscopic ultrasound-fine needle (EUS-FNA) aspiration is currently performed with 19,22 , and 25 gauge needles, whereas EBUS-TBNA needles are available in 4 sizes: 19, 21, 22, and 25 gauge. All these needles have a removable stylet that is consisted of a retractable sharp or smooth tip and a sheath, and a proximal port through which the suction is applied. EBUS-TBNA and EBUSFNA needles $(19,21,22$, and 25 gauge) can obtain cytology and histology samples. ${ }^{10,11}$ There are not sufficient studies that demonstrate the higher diagnostic accuracy of endoscopic ultrasound-fine needle aspiration performed with a 22-gauge needle instead of a 25 -gauge needle, despite the larger diameter. The strength of the 22-gauge needle is the acquisition of a larger portion of tissue, whereas the 25-gauge needle facilitates the puncture. Therefore, the choice of both the sample type and needle depends on the targeted lesion and local expertise. ${ }^{12,13}$ Also, for TBNA, the needle size ( 21 or 22 gauge) does not influence the diagnostic yield. ${ }^{14}$ However, the larger tissue samples obtained with the larger needles can be useful for ancillary testing, including immunohistochemistry and molecular analysis, which may be crucial for targeted therapy.

The cytology approach with rapid on-site evaluation does not significantly increase the diagnostic efficacy of fine needle aspiration on lung cancer diagnosis and staging but may decrease the complication rate. ${ }^{15,16}$ In particular, the use of rapid on-site evaluation during TBNA reduces the number of needle passes, the procedural time, the repetition of other diagnostic tests (ie, additional bronchoscopic procedures), and costs. ${ }^{17}$

\section{Technique}

EBUS-TBNA and endoscopic ultrasound with bronchoscope-fine needle aspiration can be safely performed as out-patient procedures. The patient should fast for $4-6 \mathrm{~h}$ before conscious sedation is administered. Endosonography is usually performed with the patient in supine position and with the operator standing at the head of the bed. The procedure consists of several phases and starts with the oral introduction of the scope. At first, the transducer must be placed on the airway wall close to the target lesion to obtain the ultrasound image. The up-down lever could help to reduce the distance between the transducer and the bronchial wall. The balloon at the distal end of the bronchoscope, inflated with sterile water, provides better ultrasound images when the target lymph nodes are located in the paratracheal areas, particularly the left side, whereas it may not be needed in subcarinal and hilar lymph node stations (7 and 11). ${ }^{18}$ The color-Doppler function is used to determine the presence of blood vessels. When putting together all these features, ultrasound images of enlarged mediastinal and/or hilar lymph nodes or lesions can be described in detail, including location, size, echogenicity, vasculation, and relation to other structures. ${ }^{18}$ Before puncturing, the needle-catheter assembly is introduced into the working channel and the system handle is locked proximal to the entrance. The needle is securely retracted, and the sheath is passed through the working channel until it is visible on the display. The needle is then unlocked and ready to execute fine needle aspiration-TBNA. ${ }^{19}$

\section{Echographic Morphology of Mediastinal Lymph Nodes}

As mentioned in the previous section, ultrasound enables the identification of lymph node features such as size, architecture, elasticity, vascular distribution, and perfusion pattern. ${ }^{20,21}$ Healthy lymph nodes have a short diameter, of $<10 \mathrm{~mm}$, a single vascular pedicle at the hilum, a triangular or oval shape, homogeneous parenchyma, and a central echogenic structure..$^{21,22}$ The predictive features of a malignant lymph node depend on size 


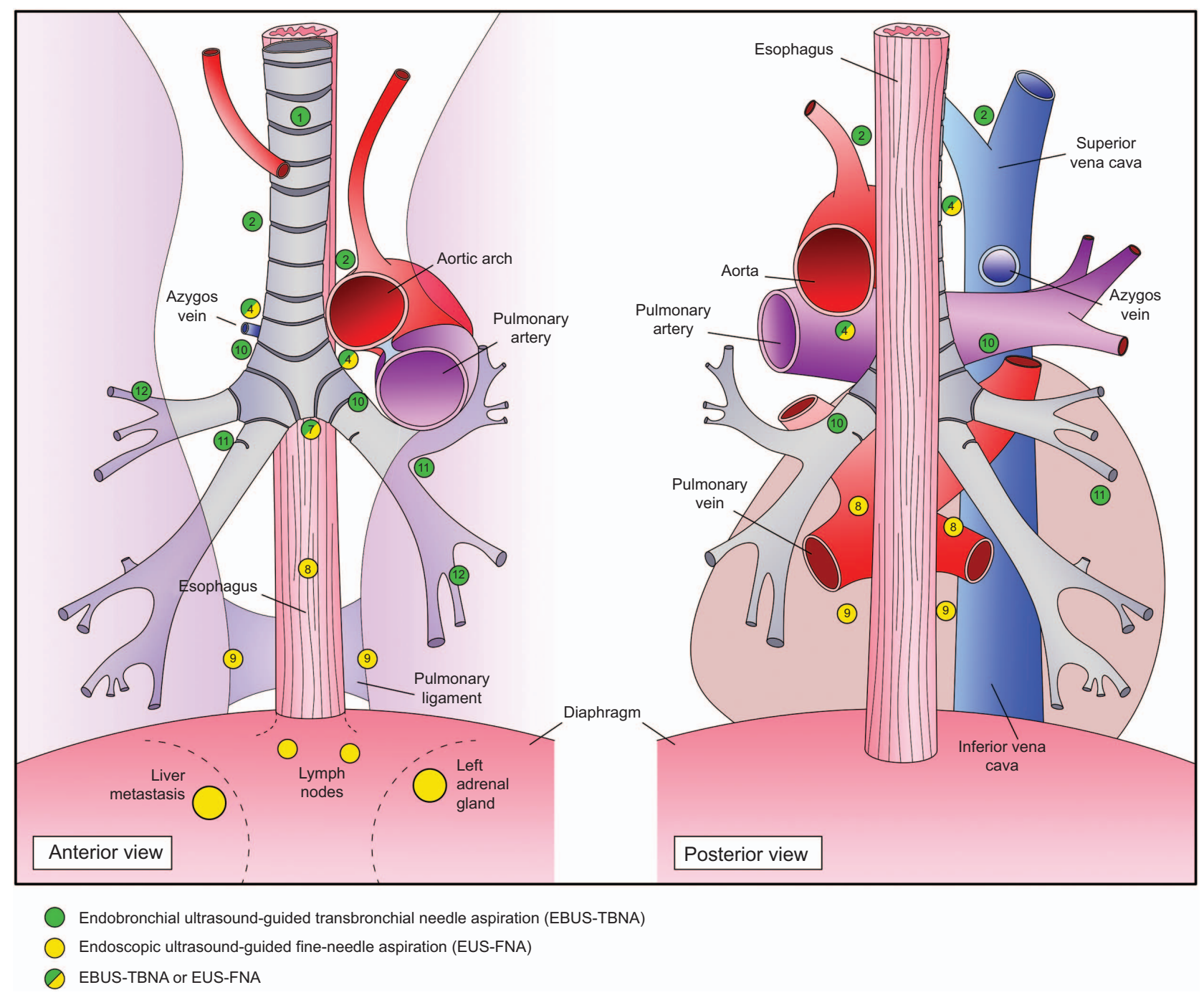

Fig. 2. Thoracic lymph nodes: 1, highest mediastinal nodes; $2 \mathrm{R}$, upper paratracheal right; 2L, upper paratracheal left; 4R, lower paratracheal right; 4L, lower paratracheal left; 7, subcarinal; 8, paraoesophageal; 9, pulmonary ligament; 10, hilar; 11, interlobare; 12, lobar.

Table 1. Endobronchial Ultrasound Equipment

\begin{tabular}{|c|c|c|c|c|c|c|c|}
\hline Endoscope & $\begin{array}{c}\text { Scope } \\
\text { Length (mm) }\end{array}$ & $\begin{array}{c}\text { Outer } \\
\text { Diameter }(\mathrm{mm})\end{array}$ & $\begin{array}{c}\text { Working } \\
\text { Channel (mm) }\end{array}$ & $\begin{array}{c}\text { Electronic } \\
\text { Probe Scanning }\end{array}$ & $\begin{array}{l}\text { Field } \\
\text { of View }\end{array}$ & $\begin{array}{c}\text { Depth of Tissue P } \\
\text { enetration }(\mathrm{mm})\end{array}$ & $\begin{array}{c}\text { Probe } \\
\text { Frequency }(\mathrm{MHz})\end{array}$ \\
\hline BF-UC180F (Olympus) & 600 & 6.3 & 2.2 & $50^{\circ}$ convex & $80^{\circ}-135^{\circ}$ & $2-50$ & $5 / 6 / 7.5 / 10 / 12$ \\
\hline EB1970UK (Pentax) & 600 & 6.9 & 2.0 & $75^{\circ}$ convex & $100^{\circ}-45^{\circ}$ & $0-120$ & $5 / 6.5 / 7.5 / 9 / 10$ \\
\hline EB-530US (Fujifilm) & 610 & 6.3 & 2.0 & $60^{\circ}$ convex & $120^{\circ}-10^{\circ}$ & $3-100$ & $5 / 7.5 / 10 / 12$ \\
\hline
\end{tabular}

Data in the column Probe Frequency represent all the frequencies choosable in each endoscope: $5 \mathrm{MHz} / 6 \mathrm{MHz} / 7.5 \mathrm{MHz} /$ etc.

(suspected of malignancy if the short-axis diameter is $>10 \mathrm{~mm}$ ) (Fig. 3), shape (triangular, round, oval, draping) (Fig. 4), echogenicity (in comparison with mediastinal structures that are hyperechoic and vascular structures that are hypoechoic), and margins. ${ }^{21}$ The diagnostic accuracy for malignancy rises to approximately $100 \%$ when the following elements are altered: size $(>10 \mathrm{~mm})$, a round or oval shape, a heterogeneous echogenicity (Fig. 5) with coagulation necrosis signs (hypoechoic areas without blood flow), and sharp margin. ${ }^{23}$ However, any suspected lymph node should be sampled regardless of echographic features because no characteristics allow the endoscopist to exclude lymph nodes for biopsy. ${ }^{24}$ 


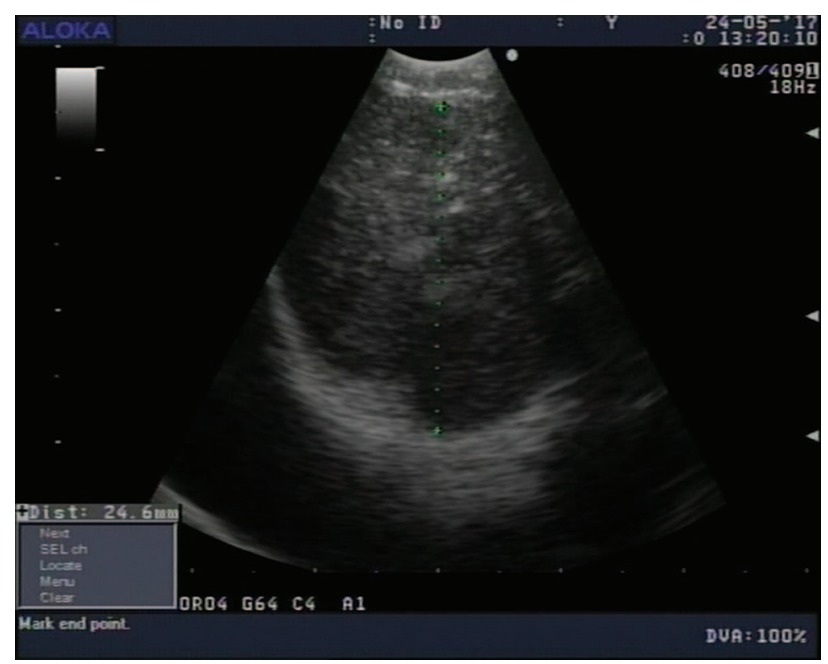

Fig. 3. Endobronchial ultrasound view of an enlarged lymph node (4R) suspected of malignancy.

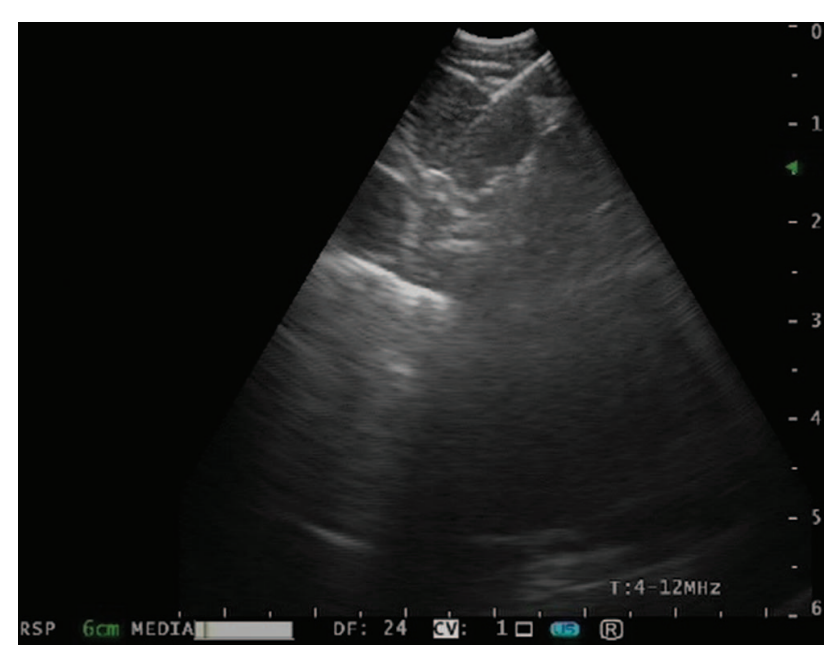

Fig. 4. Endobronchial ultrasound-transbronchial needle aspiration of a lymph node (4L), presenting an irregular shape.

\section{Suction Versus Non-Suction}

After the recognition of a lymph node or mass under real-time ultrasound guidance, the needle is introduced through the working channel and the stylet remains in place during the first puncture and is also used to clean the tip of the needle of contaminating bronchial cells. Technically, the stylet is removed when the needle enters the target, and it is replaced with a negative pressure syringe $(20 \mathrm{~mL})$ if suction is elected to be used. ${ }^{25}$ Multiple agitations are made with the needle within the node or mass to obtain a sufficient specimen. With regard to EBUS-TBNA, a prospective study by Lee et $\mathrm{al}^{26}$ demonstrates that 3 passes per site are suitable to obtain enough material for the diagnosis and staging of patients with proven or suspected

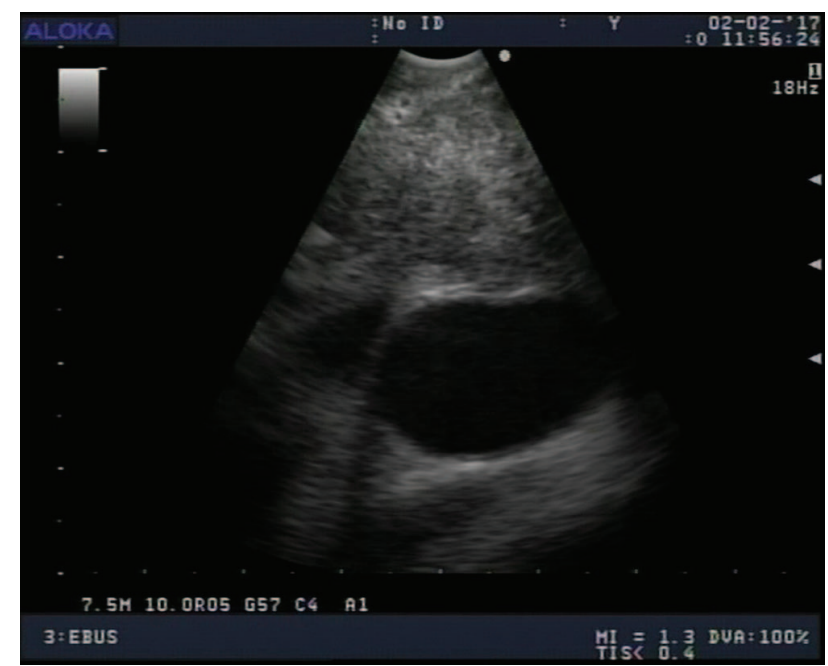

Fig. 5. Endobronchial ultrasound view of a lymph node (4L), presenting an heterogeneous echogenicity.

lung cancer. However, a minimum of 4 needle passes may provide an adequate amount of specimen for immunohistochemistry and advanced molecular marker analysis. ${ }^{27}$ Moreover, additional material is requested in cases of suspected lymphoma, sarcoidosis, or benign diseases. ${ }^{28,29} \mathrm{With}$ regard to EBUS-TBNA, suction must be avoided after an initial bloody specimen or when the material is collected to perform rapid on-site evaluation. ${ }^{30}$ This practice agrees with a number of studies that demonstrated a better adequacy of different fine-needle aspiration specimens when aspiration has not been used. ${ }^{30}$ The absence of suction decreases tissue trauma and the number of blood cells collected by the needle. Currently, there are not sufficient data that demonstrate what kind of technique is more adequate, and both EBUS-TBNA puncture with and EBUSTBNA puncture without suction are considered acceptable methods. ${ }^{30}$

\section{Adequacy Criteria for EBUS Specimens}

EBUS-TBNA aims to obtain an adequate specimen for diagnosis and, in case of malignancy, for mediastinal tumor staging and subtyping. An accepted standard definition to establish the specimen adequacy, in particular, for lymph nodes, is still missing. Samples should be rich in lymphocytes and/or lymphohistiocytic aggregates, and, when the specimen is poor, the number of lymphocytes should be higher than blood contamination alone. Any smear with lymphocytes-lymphoid tissue such as $>40$ lymphocytes per high-power field or $>5$ low-power fields with $>100$ lymphocytes in each and $<2$ bronchial cell groups per low-power field is considered adequate. ${ }^{31}$ The latter criterion is helpful to avoid misinterpretation of chronically inflamed lung parenchyma as an adequate lymph 
node. ${ }^{32}$ The sample is clearly diagnostic when numerous neoplastic cells and scarce lymphocytes or histiocytes are present. ${ }^{31}$ The sample is considered not acceptable when there is high endobronchial contamination, such as mucus or ciliated bronchial cells, or hemodilution.

\section{Ultrasound Techniques in the Diagnosis and Staging of Lung Cancer}

Lung cancer is one of the most common malignancies and accounts for very high cancer-related mortality. In the absence of distant metastases, mediastinal lymph node staging is the most important factor that affects the management and prognosis of patients diagnosed with lung cancer. Clinical staging of lung cancer is usually performed first by radiological imaging, which describes the tumor involvement of regional lymph nodes, followed by cytological and/or histological sampling. EBUS-TBNA and endoscopic ultrasound-fine needle aspiration are minimally invasive procedures performed to this aim. Most of the studies on EBUS-TBNA staging follow a systematic approach by evaluating representative nodes from each node station. ${ }^{4}$ However, one approach selectively targets enlarged lymph nodes detected by either computed tomography (CT) or CT and positron emission tomography (PET). When comparing results from studies that used a systematic approach with those that used a more selective approach, only small differences have been reported. ${ }^{4}$ However, the level of meticulousness (systematic or selective) may be less important in patients diagnosed with suspected $\mathrm{N} 2,3$ disease. At this point, there are not sufficient data available to clearly establish the impact of a global or a limited lymph node assessment. ${ }^{4}$

\section{Mediastinoscopy Versus Endosonography}

Mediastinoscopy is a surgical procedure for the sampling of mediastinal lymph nodes considered as the accepted standard for a long period of time (sensitivity of 78\%). ${ }^{33}$ Mini-invasive surgical methods (video-assisted mediastinoscopy and video-assisted mediastinoscopy lymphadenectomy, and video-assisted thoracoscopic surgery) have been developed for mediastinal staging of nonsmall-cell lung cancer to allow a better visualization and a better lymph node yield.4,34 Locoregional staging (cT4N2-3) has been improved by adding the endoscopic ultrasound procedure to mediastinoscopy, owing to the possibility to reach different nodal stations and the ability to assess mediastinal tumor invasion. ${ }^{35}$ Several prospective studies compared EBUS-TBNA diagnostic achievement with that of mediastinoscopy applied to patients with enlarged mediastinal lymph nodes on CT or high uptake on PET. ${ }^{36,37}$ Some, but not all, studies show a higher EBUSTBNA has a higher diagnostic accuracy (91\%) than me- diastinoscopy $(78 \%, P=.007)$ per lymph node analysis, especially for the diagnostic yield at station 7 (79\% for mediastinoscopy vs $98 \%$ for EBUS-TBNA, $P=.007$ ) and at station $4 \mathrm{~L}(52.4$ vs $81 \%, P=.027) .{ }^{9}$

A recent meta-analysis confirmed that EBUS-TBNA and mediastinoscopy have a similar performance if compared in mediastinal lymph node staging in lung cancer. ${ }^{38}$ Moreover, EBUS-TBNA proved to be less invasive and better tolerated, and with fewer complications. A matter of discussion is if patients whose disease is staged as negative by endosonography should undergo surgical staging of the mediastinum. The ASTER trial ${ }^{6}$ showed a greater sensitivity of staging by combined endosonography (EBUS and endoscopic ultrasound), followed by surgical staging (in the case of the absence of nodal metastases) versus surgical staging alone for mediastinal node metastases. In addition, the use of mediastinoscopy after a negative endosonography finding improved the sensitivity of mediastinal nodal staging up to $94 \% .{ }^{6}$ Jenssen et $\mathrm{al}^{23}$ recommended that negative endosonography findings should be surgically verified in patients with suspicious lymph nodes on CT or PET. Indeed, the sensitivities of surgery (79\%), endosonography $(85 \%)$ (EBUS and endoscopic ultrasound), and negative endosonography followed by surgery $(94 \%){ }^{39}$

\section{EBUS-TBNA and Endoscopic Ultrasound-Fine Needle Aspiration}

Recent meta-analyses showed a pooled sensitivity of EBUS-TBNA for lung cancer in the range of 88 to $93 \%, 4,40-43$ and a comparable diagnostic efficiency was reported for endoscopic ultrasound-fine needle aspiration. Two meta-analyses reported a pooled sensitivity of endoscopic ultrasound-fine needle aspiration in nodal staging of nonsmall-cell lung cancer of 83 and $89 \% .4,44$ Several studies demonstrated that a combined EBUS and endoscopic ultrasound approach improves diagnostic yield in lymph node staging versus each of the techniques alone. ${ }^{6,7}$ The sensitivity increased by $21 \%$, in average, compared with the esophageal approach alone (pooled data from 7 studies) and by $13 \%$ compared with EBUS-TBNA alone (pooled data from 9 studies). ${ }^{5}$ The sensitivity of both EBUS and endoscopic ultrasound for mediastinal lymph node staging is approximately $90 \% .4,7,35,43,45$

A remarkable study focused on identifying predictors of false-negative results in 775 patients with non-small-cell lung cancer staged negative by EBUS, endoscopic ultrasound, or combined endoscopic ultrasound and EBUS, and retrospectively analyzed. ${ }^{46}$ Three variables (central location of the lung tumor, nodal enlargement on $\mathrm{CT}$ and Fludeoxyglucose (FDG) avidity for N2/N3 on PET) are associated with false-negative endoscopic ultrasound and/or EBUS outcomes. By combining these variables in 


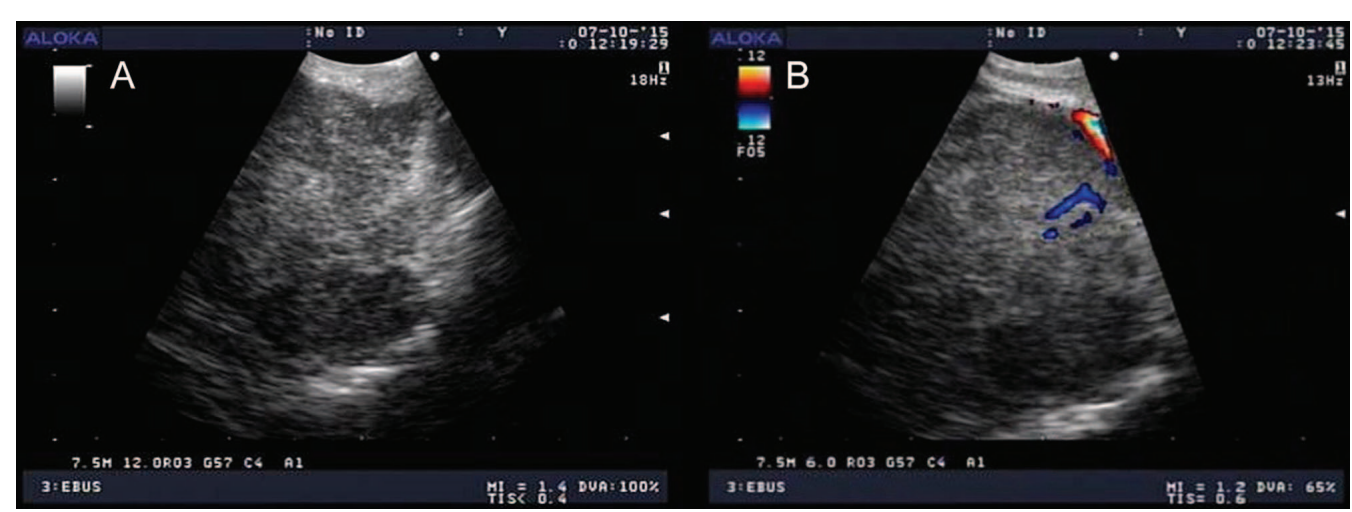

Fig. 6. Endobronchial ultrasound view (A) and endoscopic ultrasound with bronchoscope (B) of the same enlarged lymph node (7).

a logistic regression model, the investigators identified subgroups of subjects who had a low probability of falsenegative endosonography outcomes. These subjects presented limited benefit from additional surgical staging, and they could directly undergo surgical resection. In detail, one subgroup (peripheral lung tumor, nodal enlargement on CT without FDG avidity for N2/N3) had a low predicted probability (7.8\%) for false-negative endoscopic ultrasound. For combined endoscopic ultrasound-EBUS, 2 subgroups were identified: peripheral located tumor with nodal enlargement on CT but without FDG avidity for N2/N3 (predicted probability, 4.7\%) and centrally located tumor without affected lymph nodes on CT or PET (predicted probability, 3.4\%). Thus, for specific well-defined subsets of patients with non-small-cell lung cancer, the low predicted probability of metastasis after negative endosonography might justify omitting confirmatory surgical staging.

\section{EBUS-TBNA and Endoscopic Ultrasound With Bronchoscope-Fine Needle Aspiration}

Endoscopic ultrasound with bronchoscope is a recently introduced procedure that consists of a transesophageal approach by using an ultrasound bronchoscope. Endoscopic ultrasound with bronchoscope enables the performance of both TBNA and fine-needle aspiration sampling with the same equipment during a single procedure and by a single operator (Fig. 6) to optimize time and maximize cost savings. ${ }^{47}$ This approach is particularly useful in patients with poor respiratory conditions or incoercible cough.

Efficacy and Diagnostic Yield. Several studies demonstrate the efficacy of the endoscopic ultrasound with bronchoscope technique in lung cancer diagnosis and staging, with a wide range of diagnostic yield, from 45.5 to $100 \%$, mainly depending on the number, size, and localization of the nodal stations. ${ }^{8,48-54}$ In these studies, the additional diagnostic gain provided by endoscopic ultrasound with bronchoscope-fine needle aspiration over EBUS-TBNA was from $2.2 \%$, as reported by Herth et $\mathrm{al}^{8}$ in 150 subjects with suspected lung cancer, to $69 \%$, as reported by Araya et $\mathrm{al}^{51}$ in 26 patients. The efficacy of endoscopic ultrasound with bronchoscope-fine needle aspiration combined with EBUS-TBNA has been remarked by a metaanalysis of 10 studies. ${ }^{55}$ The combined sensitivity of both of the procedures was $91 \%$, which was significantly higher than the pooled sensitivity of EBUS-TBNA alone (80\%), and the pooled additional diagnostic gain by adding endoscopic ultrasound with bronchoscope was $7.6 \%$.

In choosing the primary procedure between EBUS and endoscopic ultrasound with bronchoscope, the addition of endoscopic ultrasound with bronchoscope-fine needle aspiration to EBUS-TBNA did not significantly increase accuracy (from 91.9 to $93.2 \%, P=.75$ ) and sensitivity (from 82.4 to $85.3 \%, P=.74$ ). On the contrary, by adding EBUSTBNA to endoscopic ultrasound with bronchoscope-fine needle aspiration, accuracy (from 86.5 to $97.3 \%, P=.02$ ) and sensitivity (from 60.0 to $92.0 \%, P=.008$ ) significantly increased. ${ }^{56}$ Thus, according to these data, EBUSTBNA seems to be a better primary procedure in endoscopic mediastinal staging.

A recent systematic review and meta-analysis aimed to describe the diagnostic accuracy and the added value of the combined use of EBUS and either endoscopic ultrasound or endoscopic ultrasound with bronchoscope in detecting mediastinal nodal metastases ( $\mathrm{N} 2 / \mathrm{N} 3$ disease). ${ }^{57}$ In the selected 13 studies (which totaled 2395 patients), the addition of endoscopic ultrasound to EBUS increased sensitivity on average by 0.12 , whereas, when adding EBUS to endoscopic ultrasound, sensitivity improved by 0.22 ; the mean sensitivity of the combined approach was 0.86 , and the mean negative predictive value was 0.92 .57

Another meta-analysis examined 12 studies (1,515 subjects) to provide a synthesis of the evidence on the diagnostic performance of EBUS plus endoscopic ultrasound in patients who underwent mediastinal staging. ${ }^{58}$ The pooled sensitivity for combined EBUS-endoscopic ultra- 
sound was $87 \%$, and the specificity was $99 \%$, and, for EBUS and endoscopic ultrasound performed with a single bronchoscope group, the sensitivity improved to $88 \%$ and specificity improved to $100 \% .{ }^{58}$ The investigators concluded that EBUS plus endoscopic ultrasound is a highly accurate and safe procedure that should be considered in selected patients with lymphadenopathy that is not accessible with conventional EBUS (Fig. 2). ${ }^{58}$ The sensitivity of endoscopic ultrasound-fine needle aspiration and EBUSTBNA for the detection of metastatic invasion in subjects selected on the basis of CT enlargement or PET positivity (inclusion criteria shared by the above-mentioned studies) was significantly higher than in subjects with negative CT findings or without any selection based on CT or PET. ${ }^{42,44}$ The combined use of endoscopic ultrasound and EBUS prevents $>50 \%$ of scheduled surgical staging procedures by diagnosing advanced disease in patients with suspected lung cancer and enlarged or PET-positive lymph nodes. ${ }^{35,59}$

Under the Dome. A crucial application for endoscopic ultrasound with bronchoscope is that of sampling of subdiaphragmatic structures, such as the left adrenal gland, the liver, and celiac nodes. Traditionally, the adrenal glands have been sampled by image-guided fine-needle aspiration performed percutaneously by using either ultrasonography or CT. However, these techniques presented a failure rate of up to $14 \%$ and were burdened with adverse events in $0.4-12 \%$ of cases. ${ }^{60,61}$ Endoscopic ultrasound-fine needle aspiration of either adrenal gland and endoscopic ultrasound with bronchoscope-fine needle aspiration of the left adrenal gland offer a less-invasive and more-accurate sampling method associated with lower adverse effects and complications rates. ${ }^{60,61} \mathrm{~A}$ retrospective study showed that 45 subdiaphragmatic biopsy procedures ( 25 left adrenal gland, 7 liver, and 13 celiac node) performed with endoscopic ultrasound with bronchoscope obtained, in all the cases, adequate samples, a large enough sample for immunohistochemistry and other ancillary tests. ${ }^{62}$ In a prospective multi-center trial, endoscopic ultrasound with bronchoscope-fine needle aspiration was compared with conventional endoscopic ultrasound-fine needle aspiration for left adrenal gland analysis in the subjects with lung cancer. ${ }^{63}$ The success rate for left adrenal gland analysis (visualized, sampled, and adequate tissue obtained) was $89 \%$ (39/44) for endoscopic ultrasound with bronchoscope-fine needle aspiration, and 93\% (41/44) for endoscopic ultrasound-fine needle aspiration. In subjects in whom the left adrenal gland was detected and sampled, sensitivity for metastatic involvement was at least $87 \%$ for endoscopic ultrasound with bronchoscope, and at least $83 \%$ for conventional endoscopic ultrasound.

Tolerability and Safety. A comparison between EBUSTBNA and endoscopic ultrasound with bronchoscope-fine needle aspiration in terms of tolerance, efficacy, and safety was performed in subjects who had lesions accessible by both EBUS-TBNA and endoscopic ultrasound with bronchoscope-fine needle aspiration and were randomized to undergo either procedure. ${ }^{64}$ Both EBUS-TBNA and endoscopic ultrasound with bronchoscope-fine needle aspiration provide high accuracy. Compared with EBUS-TBNA, endoscopic ultrasound with bronchoscope-fine needle aspiration was associated with a shorter duration of the procedure, lower doses of intravenous midazolam and intraairway lidocaine, less-frequent oxygen desaturations, and higher operator satisfaction. In addition, no major complications have been reported, and endoscopic ultrasound with bronchoscope-fine needle aspiration proved to be a safe procedure. ${ }^{64}$

\section{Cytology and Ancillary Testing}

Both EBUS-TBNA and endoscopic ultrasound-fine needle aspiration provide excellent specimens that have proven to be well suited for ancillary testing, such as immunohistochemistry and tumor genotyping. With regard to the cytology of specimens, 2 considerations are worth mentioning. First, the operator must avoid collecting cellular contaminants (eg, bronchial columnar cells, histiocytes, fragments of cartilage, mesothelial cells, or glandular cells derived from submucosal seromucinous glands) during the needle pass through the tracheal wall, ${ }^{31}$ and the pathologist should be careful to not misinterpret these benign cells. Second, EBUS-TBNA tumor specimens are used for both staging and subtyping the disease, so samples have to be large enough to perform molecular testing. Sample adequacy has been discussed above in the "adequacy criteria for EBUS specimens" section.

Generally, when cytomorphology alone is insufficient for a definitive characterization, an initial limited panel of immunohistochemical markers is recommended, including adenocarcinoma (thyroid transcription factor 1 or napsin A) and squamous cell markers (p63, p40, or cytokeratin 5/6). ${ }^{31}$ Non-small-cell lung cancer should also be tested for the presence of a driver mutation [such as epidermal growth factor receptor (EGFR), anaplastic lymphoma receptor tyrosine kinase (ALK), c-ros oncogene 1 receptor tyrosine kinase (ROS1), or Programmed death-ligand 1 (PD-L1)] that can be specifically treated with a targeted therapy. EBUS-TBNA successfully acquires adequate cellular materials for tumor genotyping in non-small-cell lung cancer, as demonstrated by several studies. ${ }^{65-69}$ In these studies, successful testing of at least one target (such as EGFR or Kirsten rat sarcoma viral oncogene homolog mutation analysis or ALK fluorescence in situ hybridization) was observed from 72 to $98 \%$ of samples. ${ }^{65-69}$ 


\section{Ultrasound Techniques in the Diagnosis of Lymphoma}

Lymphoma is one of the common differential diagnoses in patients with mediastinal lymphadenopathy. Current guidelines recommend surgical excision biopsy as the accepted standard for diagnosis, nodal architecture assessment, phenotypic and molecular studies, ${ }^{70-74}$ because treatment depends on precise lymphoma subtyping. Needlecore and endoscopy biopsies should be reserved when surgical risk is excessively elevated, and fine-needle aspirate is considered inappropriate or not recommended. The role of fine-needle aspiration cytology for lymphoma diagnosis is still controversial. One of the negative points for such a test is the lack of tissue architecture preservation compared with surgical excisions. However, in the current World Health Organization classification, ${ }^{75}$ lymphomas are distinguished, not only on the basis of tissue architecture but also on immunophenotypic, cytogenetic, and molecular features, the latter tests even being feasible on cytology samples. Given the undoubtedly high diagnostic yield of EBUS-TBNA for nodal staging of non-small cell lung cancer, this tool has also been tested for the diagnosis of mediastinal lymphomas.

\section{Diagnostic Approach}

One of the largest studies was conducted by Moonim et $\mathrm{al},{ }^{28}$ which prospectively evaluated the diagnostic performance of EBUS-TBNA in a subtype diagnosis of de novo and relapsed mediastinal lymphomas. In this study, a consultant cytopathologist performed rapid on-site evaluation in the operating room, and the final diagnosis was formulated after multidisciplinary team consultation. ${ }^{28}$ The results were excellent, both for diagnosis and for subtyping of lymphomas into 3 categories (high-grade non-Hodgkin lymphoma, low-grade non-Hodgkin lymphoma, and Hodgkin lymphoma). ${ }^{28}$ An EBUS-TBNA diagnosis was adequate for clinical management in 84 of 100 cases (84\%). ${ }^{28}$ A systematic review focused on this topic, which revealed discrepancies and heterogeneity among studies, with an overall sensitivity, NPV (Negative Predictive Value), and diagnostic accuracy range of $38-91 \%, 83-96.4 \%$, and $91-$ $97 \%$, respectively. ${ }^{76}$

Most of the analyzed studies were retrospective, nonrandomized, non-controlled, and conducted on small cohorts. ${ }^{76}$ Sub-classification of lymphomas was found to be even more problematic, with reported rates that ranged from 38 to $88.8 \%$, as highlighted by another review. ${ }^{77}$ More recently, Grosu et al ${ }^{78}$ retrospectively estimated the diagnostic ability of EBUS-TBNA. They used likelihood ratios to quantify the ability of EBUS-TBNA to diagnose lymphoma and sensitivity and specificity for lymphoma subtyping. Rapid on-site evaluation and cytopathological assistance were available. EBUS-TBNA was able to establish a diagnosis of lymphoma in 63 of 75 subjects (84\%). The sensitivity of EBUS-TBNA for subtyping was $77 \% .78$ A significant increase in diagnostic accuracy for lymphomas was obtained by using EBUS-guided miniforceps instead of needles in the biopsy of paratracheal, subcarinal, and hilar nodes. ${ }^{79,80}$ However, after these promising results, no further experiences have been published up to now, and, therefore, no definitive conclusion can be drawn about this technique.

\section{Specimen Handling}

The cytopathological assistance for handling, processing, and interpretation of the specimen is deemed a critical point in the EBUS-TBNA diagnostic possibility for lymphoma. EBUS-TBNA can provide adequate material for cytomorphology, which is the first step of the evaluation. The specimen could also be suitable for additional ancillary tools, such as flow cytometry, immunophenotyping, immunohistochemistry, and microbiology. The presence of an experienced cytopathologist for rapid on-site evaluation could warrant specimen adequacy and triage ${ }^{81}$ Flow cytometry could establish B-cell clonality and is helpful in sub-classifying some lymphomas. Immunohistochemistry staining on cell-block sections is another ancillary test with widespread use. Cytogenetics or fluorescence in situ hybridization (FISH) can be useful for identifying chromosomal translocations. Both cell block sections and cytology smears can be suitable for FISH assay.

Much criticism has been laid at inadequate sampling of fine-needle aspiration for the diagnosis of lymphoma. A multidisciplinary team coordination among radiologists, endoscopists, hematopathologists, and oncologists is needed to minimize such inadequacy. ${ }^{77}$ Rates of diagnostic success could significantly vary among lymphoma subtypes. ${ }^{82}$ Chronic lymphocytic lymphoma and mantle-cell lymphoma could be identified by using fine-needle aspiration in conjunction with pertinent ancillary tests. On the contrary, a diagnosis of Hodgkin lymphoma by using cytology could be very difficult due to inherent limitations of tissue sampling (hypocellularity, lack of clonal population, loss of architecture, rarity of Reed-Sternberg cells). ${ }^{83} \mathrm{Ad}-$ equate grading of follicular lymphoma on cytological material could be particularly difficult. ${ }^{84}$ The use of a larger needle size, such as 19 gauge, could overcome the limitations of cytology in this field. A review by GimenoGarcía et al ${ }^{85}$ analyzed 5 studies that used endoscopic ultrasound biopsy with core needles. In this series, lymphoma diagnosis was obtained in $94 \%$ of the cases and sub-classification according to the World Health Organization criteria was possible in $85 \%$ of the cases. ${ }^{85}$ 


\section{Perspectives}

The expanding role of genetic testing in the field of hematopoietic malignancies could help clinicians to go beyond the need for tissue morphology. In the future, novel molecular and genetic testing, such as next-generation sequencing, could become routinely applied to the diagnostic workup of patient specimens; EBUS-fine needle aspiration samples could be fit for these options. ${ }^{86,87} \mathrm{New}$, prospective trials are urgently needed to throw light on the diagnostic possibilities of EBUS and endoscopic ultrasound-fine needle aspiration in the field of lymphomas; with the close collaboration of dedicated and experienced cytopathologists. With the development of newer, reliable, ancillary cytology tools, endosonography could possibly become the first-line test for mediastinal lymphomas in the future, and thus replicate the brilliant results obtained in solid tumors, for example, lung cancer. A significant increase in diagnostic accuracy for lymphomas was obtained by using EBUS-guided miniforceps instead of needles in the biopsy of paratracheal, subcarinal, and hilar nodes.

\section{Ultrasound Techniques in the Diagnosis of Sarcoidosis}

Flexible bronchoscopy and ancillary bioptic techniques, including endobronchial biopsy, transbronchial lung biopsy, and TBNA have been extensively used for diagnosis, especially in stage 1 or stage 2 sarcoidosis. In recent years, a meta-analysis indicated a satisfying diagnostic yield for conventional blind TBNA, of $62 \%$, and also showed that the addition of transbronchial biopsy (TBB) to TBNA could even increase the diagnostic yield up to $83 \% .{ }^{88}$ Different studies compared EBUS-TBNA with conventional bronchoscopic techniques for the diagnosis of sarcoidosis. ${ }^{89-95}$ A 2013 randomized study in a highly selected population showed a higher diagnostic yield for EBUS or endoscopic ultrasound $(80 \%, 95 \%$ CI $73-86 \%)$ versus conventional bronchoscopy with endobronchial biopsy plus TBB $(53 \%, 95 \%$ CI $45-61 \%) .{ }^{95}$ In 2014, another randomized trial compared the diagnostic yield of conventional TBNA (cTBNA) versus EBUS-TBNA, with TBB and endobronchial biopsy being performed in all the cases. EBUS-TBNA had the highest individual yield as a standalone test, even if the comparison with TBB was not statistically significant. In the EBUS-TBNA group, the diagnostic yield was statistically significantly superior compared with the cTBNA group, and the addition of TBB to both groups significantly improved the diagnostic performance, without increasing the rate of adverse events. ${ }^{96}$ The lack of superiority for EBUS-TBNA versus TBB in this study could be explained by the fact that $>50 \%$ of the study population had pulmonary infiltrates. ${ }^{97} \mathrm{~A}$ recent metaanalysis reported an excellent diagnostic yield for EBUS-
TBNA, which further confirmed that additional techniques, such as TBB and endobronchial biopsy, could increase the diagnostic performance, even though significant heterogeneity was found among selected studies. ${ }^{98}$

To determine the diagnostic value of EBUS-TBNA in unselected populations, Trisolini et al ${ }^{99}$ performed a metaanalysis that included 14 studies. The results confirmed an excellent diagnostic performance for EBUS-TBNA (pooled diagnostic yield, 79\%; sensitivity, 84\%), although, a significant inter-study heterogeneity in sensitivity was observed. ${ }^{99}$ A recent randomized study showed the best diagnostic yield (75\%) for endoscopic ultrasound-fine needle aspiration as a standalone test compared with EBUS-TBNA (64\%). The combination of the 2 endosonographic techniques showed sensitivity and accuracy of $80 \%$, whereas the combination of the standard bronchoscopic procedures led to an accuracy of $64 \%$. The diagnostic yield was higher for endoscopic ultrasound compared with EBUS, but this was not statistically significant. ${ }^{100}$ These observations were further confirmed by a retrospective analysis. ${ }^{101}$ The addition of a rapid on-site evaluation to EBUS-TBNA did not seem to increase the diagnostic yield, whereas a rapid on-site evaluation could greatly increase the diagnostic performance of cTBNA. ${ }^{102}$ More recently, a preliminary experience with a flexible 19-gauge EBUS-TBNA needle demonstrated a diagnostic yield of $93 \%$ for sarcoidosis, which hints that a larger lumen could increase the likelihood of finding non-caseating granulomas. ${ }^{11}$ However, these results need confirmation by means of prospective, larger studies. In conclusion, the definitive response about the role of endosonography as standalone test for sarcoidosis is yet to come. Thus far, the utility of adding airways and parenchymal biopsies should not be neglected, and clinicians should combine all the available biopsy techniques to increase the diagnostic yield. ${ }^{103}$

\section{Ultrasound Techniques in the Diagnosis of Infections}

EBUS-TBNA has also been used for the diagnosis of infectious diseases, mainly Mycobacterium tuberculosis and Histoplasma capsulatum. Intrathoracic tuberculous lymphadenopathy is a far from rare manifestation of pulmonary tuberculosis. The clinical diagnosis could be challenging due to a lack of distinctive clinical and radiological signs. The first 2 cases of tuberculous lymphadenitis diagnosed with EBUS-TBNA were described in 2009. ${ }^{104}$ Other researchers described endoscopic ultrasound-fine needle aspiration of tuberculous mediastinal lymphadenopathy. ${ }^{105,106}$ Navani et al ${ }^{107}$ studied 156 consecutive subjects with isolated intrathoracic tuberculosis lymphadenitis. They found that EBUS-TBNA was diagnostic of tuberculosis in $94 \%$ of the subjects when combining pathological findings and microbiological investigations. ${ }^{107}$ 
EBUS-TBNA histopathology was diagnostic or suggestive of tuberculosis in $86 \%$ of the subjects, whereas, in 47\%, a positive culture of $M$. tuberculosis was obtained. 107 Similar results were found in a 2013 Chinese study 108 and in a more recent retrospective Turkish study. ${ }^{108,109}$ Similar culture rates were found for mediastinoscopy, ${ }^{110}$ whereas variable culture rates were found for endoscopic ultrasound-fine needle aspiration, ${ }^{106,111,112}$ and lower rates for TBNA without EBUS. ${ }^{113,114}$ More elevated culture rates (62\%) were found by a retrospective Australian study. ${ }^{115}$ The low culture rates in mediastinal tuberculous lymphadenopathy may be due to the scarcity of bacillary load in the lymph node, insufficient suitable cellular material sampling, and technical difficulties in culturing M. tuberculosis. A recent meta-analysis found a culture-positive rate of $54 \%$ for EBUS-TBNA, with significant heterogeneity among included studies. ${ }^{116}$ The pooled diagnostic yield of EBUS-TBNA for mediastinal tuberculous lymphadenopathy was $80 \% .{ }^{116}$ These results were confirmed by another almost concomitant meta-analysis that included 809 subjects from 8 different studies. ${ }^{117}$ The calculated pooled sensitivity and specificity of EBUS-TBNA for a diagnosis of intrathoracic tuberculosis were $80 \%$ and $100 \%$, respectively. ${ }^{117}$

Various articles tried to address whether nucleic acid amplification tests could be useful for the diagnosis of tuberculous lymphadenopathy. The results were contrasting, with sensitivities that ranged from approximately 56 to $38 \% .{ }^{118,119}$ The Xpert MTB/RIF (Cepheid, Sunnyvale, California), a highly specific integrated polymerase chain reaction assay, ${ }^{120}$ was tested on EBUS-TBNA samples from 88 cases of patients with definite tuberculosis. Xpert demonstrated an overall sensitivity for culture-positive tuberculosis of $72.6 \% .{ }^{121}$ An additional role for an Xpert MTB/ RIF assay was also suggested by a recent Korean study, even if the results were limited by the small number of subjects. ${ }^{122}$ Few studies have addressed the usefulness of EBUS-TBNA in subjects infected with the human immunodeficiency virus. ${ }^{123-125}$ The largest of these studies was recently published and showed a high diagnostic yield for EBUS-TBNA for tuberculosis lymphadenitis. ${ }^{125}$ Nonetheless, this study included also malignancies, so it is hard to draw definitive conclusions. ${ }^{125}$ Due to the overall good diagnostic yield, EBUS-TBNA should be considered the procedure of choice in the diagnostic workup of all the cases in which tuberculous lymphadenopathy is suspected. Knowledge regarding the usefulness of EBUS-TBNA for fungal and non-mycobacterial infections is scarce and limited to case series. ${ }^{126-128}$ It seems that EBUS-TBNA has a limited role for fungal infections. Caseating granulomas seems to be more commonly associated with a positive lymph node fungal stain and culture. ${ }^{129}$

In conclusion, apart from M. tuberculosis, Mycobacterium avium, or endemic fungal infection, EBUS-TBNA
Table 2. Severe and Minor EBUS-TBNA and EUS-FNA Complications

\begin{tabular}{|c|c|}
\hline \multicolumn{2}{|l|}{ Adverse Events } \\
\hline Severe & Minor \\
\hline \multicolumn{2}{|l|}{ EBUS-TBNA } \\
\hline $\begin{array}{l}\text { Pneumothorax and/or } \\
\text { pneumomediastinum }\end{array}$ & $\begin{array}{l}\text { Bleeding at puncture } \\
\text { site }\end{array}$ \\
\hline Massive bleeding & Cough \\
\hline Severe cough & Fever \\
\hline $\begin{array}{l}\text { Infections (mediastinitis, mediastinal } \\
\text { abscess, pleuropericarditis, } \\
\text { pneumonia, sepsis) }\end{array}$ & $\begin{array}{l}\text { Bradycardia } \\
\text { Hypotension }\end{array}$ \\
\hline $\begin{array}{l}\text { Airway edema and/or hypoxemia } \\
\text { Respiratory failure or arrest } \\
\text { Left-sided mainstem bronchus laceration } \\
\text { Needle fracture }\end{array}$ & Sore throat \\
\hline \multicolumn{2}{|l|}{ EUS-FNA } \\
\hline $\begin{array}{l}\text { Infections (mediastinitis, mediastinal abscess, } \\
\text { pleuropericarditis, pneumonia, } \\
\text { sepsis) }\end{array}$ & $\begin{array}{l}\text { Abdominal and/or } \\
\text { chest pain } \\
\text { Fever }\end{array}$ \\
\hline Mediastinal bleeding and hematomas & Sore throat \\
\hline Esophageal perforation & Stridor \\
\hline $\begin{array}{l}\text { EBUS }=\text { endobronchial ultrasound } \\
\text { TBNA }=\text { transbronchial needle aspiration } \\
\text { EUS }=\text { endoscopic ultrasound } \\
\text { FNA }=\text { fine-needle aspiration }\end{array}$ & \\
\hline
\end{tabular}

samples submitted for routine microbiological studies have minimal clinical utility due to frequent bacterial contamination and inadequate sensitivity to exclude infectious causes of lymphadenopathy. ${ }^{130}$ Nevertheless, the role of fine-needle aspiration cytology in diagnosing infections has greatly expanded. The collaboration of dedicated cytopathologists and cytotechnologists to attend a TBNA, provide rapid on-site evaluation, triage the slides, and perform special stains and ancillary tests, seems to be a crucial point and one of the major challenges in this field. ${ }^{131}$ Larger, prospective studies in which cytopathologists and microbiologists are actively involved are needed to address this topic.

\section{Complications}

Few reliable data are available on the safety of endoscopic ultrasonography, mainly because follow-up of patients for possible complications is not always performed in routine practice. Nevertheless, as the procedures have become widespread, descriptions of severe complications have increased and endosonography has proven to be a fairly safe technique with a serious adverse events rate of $<1 \%$ when using the combined approach of EBUS-endoscopic ultrasound ${ }^{57}$ (Table 2). von Bartheld et al ${ }^{132}$ reviewed 190 articles with $>16,000$ subjects who underwent 
EBUS-endoscopic ultrasound, and no fatal outcomes were found. All deaths reported in the literature occurred in subjects with compromised performance status. In these patients, endoscopic ultrasound is usually preferred to EBUS because of its tolerability. ${ }^{133}$ Infectious complications, such as mediastinitis and mediastinal abscess formation, were the main severe adverse events (overall rate of $0.14 \%$ ) reported by von Bartheld et al. ${ }^{132}$ Only 2 cases of severe infectious complications in patients with lung cancer has been found, mostly in patients at risk (patients affected by diabetes mellitus, ${ }^{134}$ sarcoidosis, or cystic lesions). Patients with infections, potentially life-threatening, should require an adequate antibiotic therapy or may undergo surgery. Oguri et al ${ }^{135}$ suggested that a large necrotic mass is more frequently associated with infectious complications, probably due to avascularity of the lesion. ${ }^{136}$ Oki et al ${ }^{64}$ advocated that, in the case of necrotic lesions, reducing the puncture numbers and performing adequate puncture may decrease infectious complications.

Gastrointestinal perforations related to endoscopic ultrasound-fine needle aspiration and pneumothorax and pneumomediastinum after EBUS-TBNA procedures has been reported. ${ }^{132}$ Pneumothorax was the most common major adverse event $(0.53 \%)$ described by an United States registry, which included $>1,300$ patients who underwent EBUS-TBNA (complication rate of $1.4 \%$ ). ${ }^{137}$ In addition, a very unusual complication is needle fracture, an event reported 3 times by Vial et al. ${ }^{138}$ This scenario could be very dangerous, especially in case the needle fragment could not be removed (only one case described in the literature). ${ }^{138}$ Severe cough, left-sided main bronchus laceration, and massive hemoptysis were also recorded as severe adverse events related to EBUS-TBNA. ${ }^{57}$ Oki et al ${ }^{64}$ found that cough was more frequent during EBUS-TBNA than during endoscopic ultrasound-fine needle aspiration and that an adequate amount of sedatives and anesthetics should be used to achieve a similar tolerance during both procedures. Seldom, severe coughing may lead to aborting the procedure.

The survey by Asano et al ${ }^{139}$ reported a higher risk of peri- or postprocedural hemorrhage $(0.68 \%)$ than did the current literature, with one case of massive hemorrhage that required prolongation of hospitalization. Minor bleeding at the puncture site is often observed but rarely requires intervention. The rate of minor adverse events is underestimated due to a lack of an accurate follow-up. von Bartheld et al ${ }^{132}$ described few minor adverse events $(0.22 \%)$, although hemoptysis, sore throat, or intractable coughing are common concerns in clinical practice. Bleeding at the puncture site occurred in 4 patients and, except for one self-limiting case, required noradrenaline injection. ${ }^{132}$ Yan et al ${ }^{140}$ found that minor or moderate bleeding was a rare complication of the EBUS-TBNA procedure. In a Korean study, the incidence of fever after EBUS-TBNA was reported to be $20 \% .{ }^{134}$ In the majority of cases, fever develops during the day after the procedure and recedes within a day; 6 subjects $(1.1 \%)$ presented with fever for $>24 \mathrm{~h}$, and 3 subjects developed infectious complications $(0.54 \%) .{ }^{134}$ However, the incidence of fever and infectious complications was underestimated because there was no long-term follow-up, and 39\% of subjects who were febrile received antibiotic treatment. ${ }^{134}$ The cause of this fever remained unknown, and it seems to have no relationship with bronchoscopic procedures. ${ }^{134}$

Only 2 more studies reported fever after EBUS-TBNA, with the limitation of estimating its incidence through a questionnaire survey: the Japanese nationwide survey ( 4 cases of fever [0.05\%] $)^{139}$ and a study, of 3,123 cases, that evaluates only fever that lasted $>24 \mathrm{~h} .{ }^{141}$ In a recent retrospective analysis of $>1,000$ procedures performed in a single center during $5 \mathrm{y}$, all the subjects were observed for a minimum of $2 \mathrm{~h}$ after EBUS-TBNA. ${ }^{142}$ Complications recorded included fever and chills, excessive coughing, chest pain, bradycardia (heart rate $<60$ beats/min), sustained hypoxemia (fall in pulse oximetric saturation of $<88 \%$ for $>1 \mathrm{~min}$ ), respiratory failure or arrest, pneumothorax, bleeding, and escalation of the level of care. ${ }^{142}$ Minor complications encountered were self-limiting, few major complications required intervention and, notably, there was no mortality. ${ }^{142}$ In conclusion, this article confirms the acceptable safety profile of endosonography. ${ }^{142}$

\section{Future Directions}

Future development for endosonography should be centered on different topics, such as an increase in diagnostic yield and safety of the procedure or develop new treatment strategies (Table 3).

\section{Elastography}

To improve the diagnostic value of EBUS-endoscopic ultrasound, one of the most promising techniques is elastography. ${ }^{143,144}$ Elastography is a real-time noninvasive strain imaging technique that measures the relative stiffness of a tissue. Some investigators used this measurement to differentiate benign from metastatic lymph nodes and to reveal the best EBUS-TBNA targets. ${ }^{145}$ Healthy or inflammatory lymph nodes present a significantly stiffer cortex than the medulla and hilum. On the contrary, the presence of metastatic infiltration appears on elastography as an increase in tissue stiffness. Several studies have been published concerning the use of elastography, a recent metaanalysis reported a sensitivity of $88 \%$ and specificity of $85 \%$ in detecting malignant from benign lymph nodes during endoscopic ultrasound elastography. ${ }^{146}$ 
Table 3. Future Directions

\begin{tabular}{ll}
\hline \hline \multicolumn{1}{c}{ Research Field } & \multicolumn{1}{c}{ Future Development } \\
\hline $\begin{array}{l}\text { Diagnosis and staging of } \\
\text { lung cancer }\end{array}$ & $\begin{array}{l}\text { Combined EBUS-EUS (-B) staging } \\
\text { Elastography } \\
\text { EUS and/or EBUS-guided confocal } \\
\text { laser endomicroscopy } \\
\text { Novel molecular and genetic testing }\end{array}$ \\
$\begin{array}{l}\text { Diagnosis and subtyping } \\
\text { of lymphoma }\end{array}$ & $\begin{array}{l}\text { Special microbiological stains } \\
\text { Diagnosis of infections } \\
\text { Therapeutic uses }\end{array}$ \\
$\begin{array}{l}\text { EBUS-guided transbronchial needle } \\
\text { injection therapy (EBUS-TBNI) }\end{array}$ \\
$\begin{array}{l}\text { Mediastinal cysts drainage } \\
\text { Training }\end{array}$ \\
$\begin{array}{l}\text { Simulator-based EBUS-EUS training } \\
\text { EBUS }=\text { endobronchial ultrasound }\end{array}$ \\
$\begin{array}{l}\text { EUS }=\text { endoscopic ultrasound } \\
\text { EUS-B }=\text { endoscopic ultrasound with bronchoscope } \\
\text { TBNI }=\text { transbronchial needle injection }\end{array}$ \\
\hline
\end{tabular}

\section{Confocal Laser Endomicroscopy}

Confocal laser endomicroscopy is an endoscopic technique performed during the endoscopic ultrasound procedure and provides real-time imaging of the mucosal layer at a subcellular level of resolution. ${ }^{147}$ The method highlights the changes in the mucosal components, such as vascular architecture, connective tissue, and cellular elements. ${ }^{147}$ These features allow endoscopists to collect realtime in vivo histological images that could improve the targeting of tissue sampling and potentially increase the diagnostic performance of endosonography. ${ }^{148,149}$

\section{Therapeutic Use of Endosonography}

Another research field deals with therapeutic uses of endosonography. Interest is growing in EBUS-guided needle injection therapy, a novel therapeutic approach for patients with isolated hilar and mediastinal recurrence of lung cancer. Khan et al ${ }^{150}$ reported in 2015 one of the first cases of local treatment of lung cancer recurrence with the application of EBUS-guided needle injection therapy with cisplatin. ${ }^{150}$ Contemporarily, Mehta et al ${ }^{151}$ and Mehta and Jantz ${ }^{152}$ published a study regarding the use of an EBUS scope and a 22-gauge EBUS needle to inject cisplatin (40 $\mathrm{mg} / 40 \mathrm{~mL}$ ie, a dose of $40 \mathrm{mg}$ of cisplatin in a solution at a concentration of $1 \mathrm{mg} / \mathrm{mL}$ [total volume $40 \mathrm{~mL}$ ]) into target lesions. The investigators performed 41 cisplatin injections in 35 subjects and obtained a $69 \%$ response rate (complete or partial response), with significantly higher survival and progression-free survival than nonresponders $(31 \%$ presented with stable or progressive disease). Two procedures were complicated by the development of bronchomediastinal fistula. ${ }^{151}$ Recently,
Parikh et al ${ }^{153}$ reported a case of a woman who presented a cavity lesion that contained aspergillomas that was treated with EBUS-guided needle injection therapy of liposomal amphotericin B.

Endosonography is a useful tool in the diagnosis of mediastinal cysts to confirm the cystic nature of the lesion (hypoechoic or anechoic appearance) and, possibly, to get cyst fluid for analysis. In symptomatic patients, surgical resection is currently the treatment of choice, ${ }^{154}$ but some investigators reported cases of TBNA performed to treat mediastinal cysts. Maturu et al, ${ }^{155}$ in 2015, performed a systematic review of these cases and focused on the role of EBUS in mediastinal cyst treatment. Thirty one of 32 analyzed subjects underwent TBNA (16 EBUS-TBNA, 15 conventional TBNA) among whom, 19 with a therapeutic intent (median aspiration volume of $50 \mathrm{~mL}$ ). ${ }^{155}$ Five subjects (16\%) experienced complications (4 infections, 1 bradycardia). ${ }^{155}$ The significant risk of infection and/or mediastinitis is the major limitation for aspirating cysts for therapeutic purposes. The investigators reported a median follow-up period of 14 months free of recurrences. ${ }^{155}$

\section{Conclusions}

Ultrasonography represents an effective tool in the evaluation of the mediastinum. When applied to endoscopic techniques, it allows the direct visualization of several mediastinal structures and the guided sampling of tissue useful for the characterization and staging of lung cancer and for the diagnosis of benign diseases. These procedures are relatively safe, with a low complication rate. Also, some future developments of endosonography could provide a further contribution in the management of patients with mediastinal diseases.

\section{ACKNOWLEDGMENTS}

We thank the architect Leonardo Giuzio for drawing the figure and Miles Davis for revising the English language.

\section{REFERENCES}

1. Dietrich CF, Annema JT, Clementsen P, Cui XW, Borst MM, Jenssen C. Ultrasound techniques in the evaluation of the mediastinum, part I: endoscopic ultrasound (EUS), endobronchial ultrasound (EBUS) and transcutaneous mediastinal ultrasound (TMUS), introduction into ultrasound techniques. J Thorac Dis 2015;7(9):E311E325.

2. Yasufuku K, Chhajed PN, Sekine Y, Nakajima T, Chiyo M, Iyoda A, et al. Endobronchial ultrasound using a new convex probe: a preliminary study or surgically resected specimens. Oncol Rep 2004; 11(2):293-296.

3. Krasnik M, Vilmann P, Larsen SS, Jacobsen GK. Preliminary experience with a new method of endoscopic transbronchial real time ultrasound guided biopsy for diagnosis of mediastinal and hilar lesions. Thorax 2003;58(12):1083-1086.

4. Silvestri GA, Gonzalez AV, Jantz MA, Margolis ML, Gould MK, Tanoue LT, et al. Methods for staging non-small cell lung cancer: 


\section{UltRASONOGRAPHY OF THE MEDIASTINUM}

Diagnosis and management of lung cancer, 3rd ed: American College of Chest Physicians evidence-based clinical practice guidelines. Chest 2013;143(5 Suppl):e211S-e250S.

5. Vilmann P, Clementsen PF, Colella S, Siemsen M, De Leyn P, Dumonceau JM, et al. Combined endobronchial and esophageal endosonography for the diagnosis and staging of lung cancer: European Society of Gastrointestinal Endoscopy (ESGE) Guideline, in cooperation with the European Respiratory Society (ERS) and the European Society of Thoracic Surgeons (ESTS). Endoscopy 2015;47:545-559.

6. Annema JT, van Meerbeeck JP, Rintoul RC, Dooms C, Deschepper E, Dekkers OM, et al. Mediastinoscopy vs endosonography for mediastinal nodal staging of lung cancer. JAMA 2010;304(20): 2245-2252.

7. Tournoy KG, Keller SM, Annema JT. Mediastinal staging of lung cancer: novel concepts. Lancet Oncol 2012;13(5):e221-e229.

8. Herth FJ, Krasnik M, Kahn N, Eberhardt R, Ernst A. Combined endoscopic-endobronchial ultrasound-guided fine-needle aspiration of mediastinal lymph nodes through a single bronchoscope in 150 patients with suspected lung cancer. Chest 2010;138:790-794.

9. Czarnecka-Kujawa K, Yasufuku K. The role of endobronchial ultrasound versus mediastinoscopy for non-small cell lung cancer. J Thorac Dis 2017;9(Suppl 2):S83-S97.

10. Nakajima T, Yasufuku K, Takahashi R, Shingyoji M, Hirata T, Itami $\mathrm{M}$, et al. Comparison of 21-gauge and 22-gauge aspiration needle during endobronchial ultrasound-guided transbronchial needle aspiration. Respirology 2011;16:90-94.

11. Tyan C, Patel P, Czarnecka K, Gompelmann D, Eberhardt R, Fortin M, et al. Flexible 19-Gauge Endobronchial Ultrasound-Guided Transbronchial Needle Aspiration Needle: First Experience. Respiration 2017;94(1):52-57.

12. Imazu H, Uchiyama Y, Kakutani H, Ikeda KI, Sumiyama K, Kaise, et al. A prospective comparison of EUS-guided FNA using 25gauge and 22-gauge needles. Gastroenterol Res Pract 2009;2009: 546390.

13. Righi L, Franzi F, Montarolo F, Gatti G, Bongiovanni M, Sessa F, et al. Endobronchial ultrasound-guided transbronchial needle aspiration (EBUS-TBNA)-from morphology to molecular testing. J Thorac Dis 2017;9(Suppl 5):S395-S404.

14. van der Heijden EH, Casal RF, Trisolini R, Steinfort DP, Hwangbo B, Nakajima T, et al; World Association for Bronchology and Interventional Pulmonology, Task Force on Specimen Guidelines. Guideline for the acquisition and preparation of conventional and endobronchial ultrasound-guided transbronchial needle aspiration specimens for the diagnosis and molecular testing of patients with known or suspected lung cancer. Respiration 2014;88(6):500-517.

15. Joseph M, Jones T, Lutterbie Y, Maygarden SJ, Feins RH, Haithcock BE, Veeramachaneni NK. Rapid on-site pathologic evaluation does not increase the efficacy of endobronchial ultrasonographic biopsy for mediastinal staging. Ann Thorac Surg 2013;96(2):403410.

16. Jain D, Allen TC, Aisner DL, Beasley MB, Cagle PT, Capelozzi VL, et al. Rapid On-Site Evaluation of Endobronchial UltrasoundGuided Transbronchial Needle Aspirations for the Diagnosis of Lung Cancer A Perspective From Members of the Pulmonary Pathology Society. Arch Pathol Lab Med 2018;142(2):253-262.

17. Oki M, Saka H, Kitagawa C, Kogure Y, Murata N, Adachi T, Ando M. Rapid on-site cytologic evaluation during endobronchial ultrasound-guided transbronchial needle aspiration for diagnosing lung cancer: a randomized study. Respiration 2013;85(6):486-492.

18. Wahidi MM, Herth F, Yasufuku K, Shepherd RW, Yarmus L, Chawla M, et al. Technical Aspects of Endobronchial UltrasoundGuided Transbronchial Needle Aspiration CHEST Guideline and Expert Panel Report. Chest 2016;149(3):816-835.
19. Vilmann P, Săftoiu A. Endoscopic ultrasound-guided fine needle aspiration biopsy: equipment and technique. J Gastroenterol Hepatol 2006;21(11):1646-1655.

20. Wang L, Wu W, Hu Y, Teng J, Zhong R, Han B, Sun J. Sonographic Features of Endobronchial Ultrasonography Predict Intrathoracic Lymph Node Metastasis in Lung Cancer Patients. Ann Thorac Surg 2015;100(4):1203-1209.

21. Fujiwara T, Yasufuku K, Nakajima T, Chiyo M, Yoshida S, Suzuki $\mathrm{M}$, et al. The utility of sonographic features during endobronchial ultrasound-guided transbronchial needle aspiration for lymph node staging in patients with lung cancer: a standard endobronchial ultrasound image classification system. Chest 2010;138(3):641-647.

22. Dietrich CF, Ponnudurai R, Bachmann Nielsen M. [Is there a need for new imaging methods for lymph node evaluation?] Ultraschall Med 2012;33(5):411-414.

23. Jenssen C, Annema JT, Clementsen P, Cui XW, Borst MM, Dietrich CF. Ultrasound techniques in the evaluation of the mediastinum, part 2: mediastinal lymph node anatomy and diagnostic reach of ultrasound techniques, clinical work up of neoplastic and inflammatory mediastinal lymphadenopathy using ultrasound techniques and h. J Thorac Dis 2015;7(10):E439-E458.

24. Wang Memoli JS, El-Bayoumi E, Pastis NJ, Tanner NT, Gomez M, Huggins JT, et al. Using endobronchial ultrasound features to predict lymph node metastasis in patients with lung cancer. Chest 2011;140(6):1550-1556.

25. Scholten EL, Semaan R, Illei P, Mallow C, Arias S, Feller-Kopman $\mathrm{D}$, et al. Stylet Use Does Not Improve Diagnostic Outcomes in Endobronchial Ultrasonographic Transbronchial Needle Aspiration: A Randomized Clinical Trial. Chest 2017;151(3):636-642.

26. Lee HS, Lee GK, Lee HS, Kim MS, Lee JM, Kim HY, et al. Real-time endobronchial ultrasound-guided transbronchial needle aspiration in mediastinal staging of non-small cell lung cancer: how many aspirations per target lymph node station? Chest 2008;134(2): 368-374.

27. Yarmus L, Akulian J, Gilbert C, Feller-Kopman D, Lee HJ, Zarogoulidis $\mathrm{P}$, et al. Optimizing endobronchial ultrasound for molecular analysis. How many passes are needed? Ann Am Thorac Soc 2013;10(6):636-643.

28. Moonim MT, Breen R, Fields PA, Santis G. Diagnosis and subtyping of de novo and relapsed mediastinal lymphomas by endobronchial ultrasound needle aspiration. Am J Respir Crit Care Med 2013;188(10):1216-1223.

29. Navasakulpong A, Auger M, Gonzalez AV. Yield of EBUS-TBNA for the diagnosis of sarcoidosis: impact of operator and cytopathologist experience. BMJ Open Respir Res 2016;3(1):e000144.

30. Harris K, Maroun R, Attwood K, Chalhoub M. Comparison of cytologic accuracy of endobronchial ultrasound transbronchial needle aspiration using needle suction versus no suction. Endosc Ultrasound 2015;4(2):115-119.

31. VanderLaan PA, Wang HH, Majid A, Folch E. Endobronchial ultrasound-guided transbronchial needle aspiration (EBUS-TBNA): an overview and update for the cytopathologist. Cancer Cytopathol 2014;122(8):561-576.

32. Nayak A, Sugrue C, Koenig S, Wasserman PG, Hoda S, Morgenstern NJ. Endobronchial ultrasound-guided transbronchial needle aspirate (EBUS-TBNA): a Proposal for on-site adequacy criteria. Diagn Cytopathol 2012;40(2):128-137.

33. Detterbeck FC, Jantz MA, Wallace M, Vansteenkiste J, Silvestri GA; American College of Chest Physicians. Invasive mediastinal staging of lung cancer: ACCP evidence-based clinical practice guidelines (2nd edition). Chest 2007;132(3 Suppl):202S-220S.

34. Adebibe M, Jarral OA, Shipolini AR, McCormack DJ. Does videoassisted mediastinoscopy have a better lymph node yield and safety 


\section{UltRASONOGRAPHY OF THE MEDIASTINUM}

profile than conventional mediastinoscopy? Interact Cardiovasc Thorac Surg 2012;14(3):316-319.

35. Annema JT, Versteegh MI, Veseliç M, Welker L, Mauad T, Sont $\mathrm{JK}$, et al. Endoscopic ultrasound added to mediastinoscopy for preoperative staging of patients with lung cancer. JAMA 2005;294(8): 931-936.

36. Um SW, Kim HK, Jung SH, Han J, Lee KJ, Park HY, et al. Endobronchial ultrasound versus mediastinoscopy for mediastinal nodal staging of non-small-cell lung cancer. J Thorac Oncol 2015; 10(2):331-337.

37. Ernst A, Anantham D, Eberhardt R, Krasnik M, Herth FJ. Diagnosis of mediastinal adenopathy-real-time endobronchial ultrasound guided needle aspiration versus mediastinoscopy. J Thorac Oncol 2008;3(6):577-582.

38. Ge X, Guan W, Han F, Guo X, Jin Z. Comparison of Endobronchial Ultrasound-Guided Fine Needle Aspiration and Video-Assisted Mediastinoscopy for Mediastinal Staging of Lung Cancer. Lung 2015; 193(5):757-766.

39. Yasufuku K, Pierre A, Darling G, de Perrot M, Waddell T, Johnston $\mathrm{M}$, et al. A prospective controlled trial of endobronchial ultrasoundguided transbronchial needle aspiration compared with mediastinoscopy for mediastinal lymph node staging of lung cancer. J Thorac Cardiovasc Surg 2011;142(6):1393-400.e1.

40. Adams K, Shah PL, Edmonds L, Lim E. Test performance of endobronchial ultrasound and transbronchial needle aspiration biopsy for mediastinal staging in patients with lung cancer: systematic review and meta-analysis. Thorax 2009;64(9):757-762.

41. Dong X, Qiu X, Liu Q, Jia J. Endobronchial ultrasound-guided transbronchial needle aspiration in the mediastinal staging of nonsmall cell lung cancer: a meta-analysis. Ann Thorac Surg 2013; 96(4):1502-1507.

42. Gu P, Zhao YZ, Jiang LY, Zhang W, Xin Y, Han BH. Endobronchial ultrasound-guided transbronchial needle aspiration for staging of lung cancer: a systematic review and meta-analysis. Eur J Cancer 2009;45(8):1389-1396.

43. Zhang R, Ying K, Shi L, Zhang L, Zhou L. Combined endobronchial and endoscopic ultrasound-guided fine needle aspiration for mediastinal lymph node staging of lung cancer: a meta-analysis. Eur J Cancer 2013;49(8):1860-1867.

44. Micames CG, McCrory DC, Pavey DA, Jowell PS, Gress FG. Endoscopic ultrasound-guided fine-needle aspiration for non-small cell lung cancer staging: A systematic review and metaanalysis. Chest 2007;131(2):539-548.

45. Annema JT, Veseliç M, Rabe KF. EUS-guided FNA of centrally located lung tumours following a non-diagnostic bronchoscopy. Lung Cancer 2005;48(3):357-361; discussion 363-364.

46. Talebian Yazdi M, Egberts J, Schinkelshoek MS, Wolterbeek R, Nabers J, Venmans BJ, et al. Endosonography for lung cancer staging: predictors for false-negative outcomes. Lung Cancer 2015; 90(3):451-456.

47. Mondoni M, D'Adda A, Terraneo S, Carlucci P, Radovanovic D, DI Marco F, Santus P. Choose the best route: ultrasound guided transbronchial and transesophageal needle aspiration with echobronchoscope in the diagnosis of mediastinal and pulmonary lesions. Minerva Med 2015;106(5):13-19.

48. Hwangbo B, Lee HS, Lee GK, Lim KY, Lee SH, Kim HY, et al. Transoesophageal needle aspiration using a convex probe ultrasonic bronchoscope. Respirology 2009;14:843-849.

49. Hwangbo B, Lee GK, Lee HS, Lim KY, Lee SH, Kim HY, et al. Transbronchial and transesophageal fine-needle aspiration using an ultrasound bronchoscope in mediastinal staging of potentially operable lung cancer. Chest 2010;138(4):795-802.

50. Bugalho A, Ferreira D, Eberhardt R, Dias SS, Videira PA, Herth FJ, Carreiro L. Diagnostic value of endobronchial and endoscopic ul- trasound-guided fine needle aspiration for accessible lung cancer lesions after non-diagnostic conventional techniques: a prospective study. BMC Cancer 2013;13:130.

51. Araya T, Demura Y, Kasahara K. Usefulness of transesophageal bronchoscopic pathologic and molecular diagnosis of lung. J Bronchology Interv Pulmonol 2013;20(2):121-126.

52. Oki M, Saka H, Ando M, Kitagawa C, Kogure Y, Seki Y. Endoscopic ultrasound-guided fine needle aspiration and endobronchial ultrasound-guided transbronchial needle aspiration: Are two better than one in mediastinal staging of non-small cell lung cancer? J Thorac Cardiovasc Surg 2014;148(4):1169-1177.

53. Szlubowski A, Zieliński M, Soja J, Filarecka A, Orzechowski S, Pankowski J, et al. Accurate and safe mediastinal restaging by combined endobronchial and endoscopic ultrasound-guided needle aspiration performed by single ultrasound bronchoscope. Eur J Cardiothoracic Surg 2014;46(2):262-266.

54. Lee KJ, Suh GY, Chung MP, Kim H, Kwon OJ, Han J, Um SW. Combined endobronchial and transesophageal approach of an ultrasound bronchoscope for mediastinal staging of lung cancer. PLoS One 2014;9(3):e91893.

55. Dhooria S, Aggarwal AN, Gupta D, Behera D, Agarwal R. Utility and Safety of Endoscopic Ultrasound With Bronchoscope- Guided Fine-Needle Aspiration in Mediastinal Lymph Node Sampling: Systematic Review and Meta-Analysis. Respir Care 2015;60(7):10401050.

56. Kang HJ, Hwangbo B, Lee GK, Nam BH, Lee HS, Kim MS, et al. EBUS-centred versus EUS-centred mediastinal staging in lung cancer: a randomised controlled trial. Thorax 2014;69:261-268.

57. Korevaar DA, Crombag LM, Cohen JF, Spijker R, Bossuyt PM, Annema JT. Added value of combined endobronchial and oesophageal endosonography for mediastinal nodal staging in lung cancer: a systematic review and meta-analysis. Lancet Respir Med 2016; 4(12):960-968.

58. Labarca G, Aravena C, Ortega F, Arenas A, Majid A, Folch E, et al. Minimally Invasive Methods for Staging in Lung Cancer: Systematic Review and Meta-Analysis. Pulm Med 2016;2016:1024709.

59. Tournoy KG, De Ryck F, Vanwalleghem LR, Vermassen F, Praet M, Aerts JG, et al. Endoscopic ultrasound reduces surgical mediastinal staging in lung cancer: a randomized trial. Am J Respir Crit Care Med 2008;177(5):531-535.

60. Patil R, Ona MA, Papafragkakis C, Duddempudi S, Anand S, Jamil LH. Endoscopic ultrasound-guided fine-needle aspiration in the diagnosis of adrenal lesions. Ann Gastroenterol Ann Gastroenterol 2016;29(3):307-311.

61. Bancos I, Tamhane S, Shah M, Delivanis DA, Alahdab F, Arlt W, et al. Diagnosis of endocrine disease: The diagnostic performance of adrenal biopsy: a systematic review and meta-analysis. Eur J Endocrinol 2016;175(2):R65-R80.

62. Meena N, Hulett C, Patolia S, Bartter T. Exploration under the dome: Esophageal ultrasound with the ultrasound bronchoscope is indispensable. Endosc Ultrasound 2016;5(4):254-257.

63. Crombag LMMJ, Szlubowski A, Stigt JA, Schuurbiers O, Korevaar DA, Bonta PI, Annema JT. EUS-B-FNA vs conventional EUS-FNA for left adrenal gland analysis in lung cancer patients. Lung Cancer 2017; 108:38-44

64. Oki M, Saka H, Ando M, Tsuboi R, Nakahata M, Oka S, et al. Transbronchial vs transesophageal needle aspiration using an ultrasound bronchoscope for the diagnosis of mediastinal lesions: a randomized study. Chest 2015;147(5):1259-1266.

65. Navani N, Brown JM, Nankivell M, Woolhouse I, Harrison RN, Jeebun V, et al. Suitability of endobronchial ultrasound-guided transbronchial needle aspiration specimens for subtyping and genotyping of non-small cell lung cancer: a multicenter study of 774 patients. Am J Respir Crit Care Med 2012;185(12):1316-1322. 


\section{UltRASONOGRAPHY OF THE MEDIASTINUM}

66. Folch E, Yamaguchi N, VanderLaan PA, Kocher ON, Boucher DH, Goldstein MA, et al. Adequacy of lymph node transbronchial needle aspirates using convex probe endobronchial ultrasound for multiple tumor genotyping techniques in non-small-cell lung cancer. J Thorac Oncol 2013;8(11):1438-1444.

67. Garcia-Olivé I, Monsó E, Andreo F, Sanz-Santos J, Taron M, Molina-Vila MA, et al. Endobronchial ultrasound-guided transbronchial needle aspiration for identifying EGFR mutations. Eur Respir J 2010;35(2):391-395.

68. Schuurbiers OC, Looijen-Salamon MG, Ligtenberg MJ, van der Heijden HF. A brief retrospective report on the feasibility of epidermal growth factor receptor and KRAS mutation analysis in transesophageal ultrasound- and endobronchial ultrasound-guided fine needle cytological aspirates. J Thorac Oncol 2010;5(10):1664-1667.

69. Nakajima T, Yasufuku K, Nakagawara A, Kimura H, Yoshino I. Multigene mutation analysis of metastatic lymph nodes in nonsmall cell lung cancer diagnosed by endobronchial ultrasound-guided transbronchial needle aspiration. Chest 2011;140(5):1319-1324.

70. Dreyling M, Geisler C, Hermine O, Kluin-Nelemans HC, Le Gouill $\mathrm{S}$, Rule S, et al. Newly diagnosed and relapsed mantle cell lymphoma: ESMO Clinical Practice Guidelines for diagnosis, treatment and follow-up. Ann Oncol 2014;25(Suppl 3):iii83-iii92.

71. Eichenauer DA, Engert A, André M, Federico M, Illidge T, Hutchings M, et al; ESMO Guidelines Working Group. Hodgkin's lymphoma: ESMO Clinical Practice Guidelines for diagnosis, treatment and follow-up. Ann Oncol 2014;25(Suppl 3):iii70-iii75.

72. Dreyling M, Ghielmini M, Rule S, Salles G, Vitolo U, Ladetto M; ESMO Guidelines Committee. Newly diagnosed and relapsed follicular lymphoma: ESMO Clinical Practice Guidelines for diagnosis, treatment and follow-up. Ann Oncol 2016;27(Suppl 5):v83v90.

73. Tilly H, Gomes da Silva M, Vitolo U, Jack A, Meignan M, LopezGuillermo A, et al; ESMO Guidelines Committee. Diffuse large B-cell lymphoma (DLBCL): ESMO Clinical Practice Guidelines for diagnosis, treatment and follow-up. Ann Oncol 2015;26(Suppl 5):v116-v125.

74. d'Amore F, Gaulard P, Trümper L, Corradini P, Kim WS, Specht L, et al; ESMO Guidelines Committee. Peripheral T-cell lymphomas: ESMO Clinical Practice Guidelines for diagnosis, treatment and follow-up. Ann Oncol 2015;26(Suppl 5):v108-v115.

75. Swerdlow SH, Campo E, Pileri SA, Harris NL, Stein H, Siebert R, et al. The 2016 revision of the World Health Organization classification of lymphoid neoplasms. Blood 2016;127(20):2375-2390.

76. Kheir F, Itani A, Assasa O, Alraiyes AH. The utility of endobronchial ultrasound-transbronchial needle aspiration in lymphoma. Endosc Ultrasound 2016;5(1):43-48.

77. Jin M, Wakely PE. Endoscopic/Endobronchial Ultrasound-Guided Fine Needle Aspiration and Ancillary Techniques, Particularly Flow Cytometry, in Diagnosing Deep-Seated Lymphomas Acta Cytol 2016;60(4):326-335

78. Grosu HB, Iliesiu M, Caraway NP, Medeiros LJ, Lei X, Jimenez CA, et al. Endobronchial Ultrasound Guided Transbronchial Needle Aspiration for the Diagnosis and Subtyping of Lymphoma. Ann Am Thorac Soc 2015;12(9):1336-1344.

79. Herth FJ, Morgan RK, Eberhardt R, Ernst A. Endobronchial ultrasound-guided miniforceps biopsy in the biopsy of subcarinal masses in patients with low likelihood of non-small cell lung cancer. Ann Thorac Surg 2008;85(6):1874-1878.

80. Chrissian A, Misselhorn D, Chen A. Endobronchial-ultrasound guided miniforceps biopsy of mediastinal and hilar lesions. Ann Thorac Surg 2011;92(1):284-288.

81. Ko HM, da Cunha Santos G, Darling G, Pierre A, Yasufuku K, Boerner SL GW. Diagnosis and subclassification of lymphomas and non-neoplastic lesions involving mediastinal lymph nodes us- ing endobronchial ultrasound-guided transbronchial needle aspiration. Diagn Cytopathol 2013;41(12):1023-1030.

82. Farmer PL, Bailey DJ, Burns BF, Day A, LeBrun DP. The reliability of lymphoma diagnosis in small tissue samples is heavily influenced by lymphoma subtype. Am J Clin Pathol 2007;128(3): 474-480.

83. Das DK, Francis IM, Sharma PN, Sathar SA, John B, George SS, et al. Hodgkin's lymphoma: diagnostic difficulties in fine-needle aspiration cytology. Diagn Cytopathol 2009;37(8):564-573.

84. Hehn ST, Grogan TM, Miller TP. Utility of fine-needle aspiration as a diagnostic technique in lymphoma. J Clin Oncol 2004;22(15): 3046-3052.

85. Gimeno-García AZ, Elwassief A, Paquin SC, Sahai AV. Endoscopic ultrasound-guided fine needle aspiration cytology and biopsy in the evaluation of lymphoma. Endosc Ultrasound 2012;1(1): 17-22.

86. Mottok A, Steidl C. Genomic alterations underlying immune privilege in malignant lymphomas. Curr Opin Hematol 2015;22(4): 343-354.

87. Slack GW, Gascoyne RD. Next-generation sequencing discoveries in lymphoma. Adv Anat Pathol 2013;20(2):110-116.

88. Agarwal R, Aggarwal AN, Gupta D. Efficacy and safety of conventional transbronchial needle aspiration in sarcoidosis: a systematic review and meta-analysis. Respir Care 2013;58(4):683-693.

89. Tremblay A, Stather DR, MacEachern P, Khalil M, Field SK. A randomized controlled trial of standard vs endobronchial ultrasonography-guided transbronchial needle aspiration in patients with suspected sarcoidosis. Chest 2009;136(2):340-346.

90. Plit M, Pearson R, Havryk A, Da Costa J, Chang C, Glanville AR. Diagnostic utility of endobronchial ultrasound-guided transbronchial needle aspiration compared with transbronchial and endobronchial biopsy for suspected sarcoidosis. Intern Med J 2012; 42(4):434-438.

91. Oki M, Saka H, Kitagawa C, Tanaka S, Shimokata T, Kawata Y, et al. Real-time endobronchial ultrasound-guided transbronchial needle aspiration is useful for diagnosing sarcoidosis. Respirology 2007; 12(6):863-868.

92. Oki M, Saka H, Kitagawa C, Kogure Y, Murata N, Ichihara S, Moritani S. Prospective study of endobronchial ultrasound-guided transbronchial needle aspiration of lymph nodes versus transbronchial lung biopsy of lung tissue for diagnosis of sarcoidosis. J Thorac Cardiovasc Surg 2012;143(6):1324-1329.

93. Nakajima T, Yasufuku K, Kurosu K, Takiguchi Y, Fujiwara T, Chiyo M, et al. The role of EBUS-TBNA for the diagnosis of sarcoidosis-comparisons with other bronchoscopic diagnostic modalities. Respir Med 2009;103(12):1796-1800.

94. Navani N, Booth HL, Kocjan G, Falzon M, Capitanio A, Brown $\mathrm{JM}$, et al. Combination of endobronchial ultrasound-guided transbronchial needle aspiration with standard bronchoscopic techniques for the diagnosis of stage I and stage II pulmonary sarcoidosis. Respirology 2011;16(3):467-472.

95. von Bartheld MB, Dekkers OM, Szlubowski A, Eberhardt R, Herth FJ, in 't Veen JC, et al. Endosonography vs conventional bronchoscopy for the diagnosis of sarcoidosis: the GRANULOMA randomized clinical trial. JAMA 2013;309(23):2457-2464.

96. Gupta D, Dadhwal DS, Agarwal R, Gupta N, Bal A, Aggarwal AN. Endobronchial ultrasound-guided transbronchial needle aspiration vs conventional transbronchial needle aspiration in the diagnosis of sarcoidosis. Chest 2014;146(3):547-556.

97. Mehta AC, Almeida FA. Choose wisely: endobronchial ultrasoundguided transbronchial needle aspiration for sarcoidosis. Chest 2014; 146(3):530-532.

98. Hu LX, Chen RX, Huang H, Shao C, Wang P, Liu YZ, Xu ZJ. Endobronchial Ultrasound-guided Transbronchial Needle Aspira- 


\section{UltRASONOGRAPHY OF THE MEDIASTINUM}

tion versus Standard Bronchoscopic Modalities for Diagnosis of Sarcoidosis: A Meta-analysis. Chin Med J 2016;129(13):1607-1615.

99. Trisolini R, Lazzari Agli L, Tinelli C, De Silvestri A, Scotti V, Patelli M. Endobronchial ultrasound-guided transbronchial needle aspiration for diagnosis of sarcoidosis in clinically unselected study populations. Respirology 2015;20(2):226-234.

100. Kocoń P, Szlubowski A, Kużdżał J, Rudnicka-Sosin L, Ćmiel A, Soja $\mathbf{J}$, et al. Endosonography-guided fine needle aspiration in the diagnosis of sarcoidosis-randomized study. Pol Arch Intern Med 2017;127(3):154-162.

101. Dziedzic DA, Peryt A, Orlowski T. The role of EBUS-TBNA and standard bronchoscopic modalities in the diagnosis of sarcoidosis. Clin Respir J 2017;11(1):58-63.

102. Madan K, Dhungana A, Mohan A, Hadda V, Jain D, Arava S, et al. Conventional Transbronchial Needle Aspiration Versus Endobronchial Ultrasound-guided Transbronchial Needle Aspiration, With or Without Rapid On-Site Evaluation, for the Diagnosis of Sarcoidosis: A Randomized Controlled Trial. J Bronchology Interv Pulmonol 2017;24(1):48-58.

103. Mondoni M, Radovanovic D, Valenti V, Patella V, Santus P. Bronchoscopy in sarcoidosis: union is strength. Minerva Med 2015; 106(2 suppl 2):1-7.

104. Steinfort DP, Johnson DF, Connell TG, Irving LB. Endobronchial ultrasound-guided biopsy in the evaluation of intrathoracic lymphadenopathy in suspected tuberculosis: a minimally invasive technique with a high diagnostic yield. J Infect 2009;58(4):309-311.

105. Puri R, Vilmann P, Sud R, Kumar M, Taneja S, Verma K, Kaushik N. Endoscopic ultrasound-guided fine-needle aspiration cytology in the evaluation of suspected tuberculosis in patients with isolated mediastinal lymphadenopathy. Endoscopy 2010;42(6):462-467.

106. Song HJ, Park YS, Seo DW, Jang SJ, Choi KD, Lee SS, et al. Diagnosis of mediastinal tuberculosis by using EUS-guided needle sampling in a geographic region with an intermediate tuberculosis burden. Gastrointest Endosc 2010;71(7):1307-1313.

107. Navani N, Molyneaux PL, Breen RA, Connell DW, Jepson A, Nankivell M, et al. Utility of endobronchial ultrasound-guided transbronchial needle aspiration in patients with tuberculous intrathoracic lymphadenopathy: a multicentre study. Thorax 2011;66(10): 889-893.

108. Sun J, Teng J, Yang H, Li Z, Zhang J, Zhao H, et al. Endobronchial ultrasound-guided transbronchial needle aspiration in diagnosing intrathoracic tuberculosis. Ann Thorac Surg 2013;96(6):2021-2027.

109. Kiral N, Caglayan B, Salepci B, Torun Parmaksiz E, Fidan A, Comert SS, Yavuzer DPM. Endobronchial ultrasound-guided transbronchial needle aspiration in diagnosing intrathoracic tuberculous lymphadenitis. Med Ultrason 2015;17(3):333-338.

110. Farrow PR, Jones DA, Stanley PJ, Bailey JS, Wales JM, Cookson JB. Thoracic lymphadenopathy in Asians resident in the United Kingdom: role of mediastinoscopy in initial diagnosis. Thorax 1985; 40(2):121-124.

111. Knox J, Lane G, Wong JS, Trevan PG, Karunajeewa H. Diagnosis of tuberculous lymphadenitis using fine needle aspiration biopsy. Intern Med J 2012;42(9):1029-1036.

112. Fritscher-Ravens A, Ghanbari A, Topalidis T, Pelling M, Kon OM, Patel K, et al. Granulomatous mediastinal adenopathy: can endoscopic ultrasound-guided fine-needle aspiration differentiate between tuberculosis and sarcoidosis? Endoscopy 2011;43(11):955961.

113. Bilaçeroğlu S, Günel O, Eriş N, Çağirici U, Mehta AC. Transbronchial needle aspiration in diagnosing intrathoracic tuberculous lymphadenitis. Chest 2004;126(1):259-267.

114. Kuo CH, Lin SM, Lee KY, Chung FT, Feng PH, Hsiung TC, et al. Algorithmic approach by endobronchial ultrasound-guided transbronchial needle aspiration for isolated intrathoracic lymphadenop- athy: a study in a tuberculosis-endemic country. J Formos Med Assoc 2014;113(8):527-534.

115. Geake J, Hammerschlag G, Nguyen P, Wallbridge P, Jenkin GA, Korman TM, et al. Utility of EBUS-TBNA for diagnosis of mediastinal tuberculous lymphadenitis: a multicentre Australian experience. J Thorac Dis 2015;7(3):439-448

116. Li W, Zhang T, Chen Y, Liu C, Peng W. Diagnostic Value of Convex Probe Endobronchial Ultrasound-Guided Transbronchial Needle Aspiration in Mediastinal Tuberculous Lymphadenitis: A Systematic Review and Meta-Analysis. Med Sci Monit 2015;21: 2064-2072.

117. Ye W, Zhang R, Xu X, Liu Y, Ying K. Diagnostic Efficacy and Safety of Endobronchial Ultrasound-Guided Transbronchial Needle Aspiration in Intrathoracic Tuberculosis: A Meta-analysis. J Ultrasound Med 2015;34(9):1645-1650.

118. Senturk A, Arguder E, Hezer H, Babaoglu E, Kilic H, Karalezli A, Hasanoglu HC. Rapid diagnosis of mediastinal tuberculosis with polymerase chain reaction evaluation of aspirated material taken by endobronchial ultrasound-guided transbronchial needle aspiration background: endobronchial ultrasound-guided transbronchial needle. J Investig Med 2014;62(6):885-889.

119. Eom JS, Mok JH, Lee MK, Lee K, Kim MJ, Jang SM, et al. Efficacy of TB-PCR using EBUS-TBNA samples in patients with intrathoracic granulomatous lymphadenopathy. BMC Pulm Med 2015;15:166.

120. Denkinger CM, Schumacher SG, Boehme CC, Dendukuri N, Pai M, Steingart KR. Xpert MTB/RIF assay for the diagnosis of extrapulmonary tuberculosis: a systematic review and meta-analysis. Eur Respir J 2014;44(2):435-446.

121. Dhasmana DJ, Ross C, Bradley CJ, Connell DW, George PM, Singanayagam A, et al. Performance of Xpert MTB/RIF in the diagnosis of tuberculous mediastinal lymphadenopathy by endobronchial ultrasound. Ann Am Thorac Soc 2014;11(3):392-396.

122. Lee J, Choi SM, Lee CH, Lee SM, Yim JJ, Yoo CG, et al. The additional role of Xpert MTB/RIF in the diagnosis of intrathoracic tuberculous lymphadenitis. J Infect Chemother 2017;23(6):381-384.

123. Han YA, Tan AH, Koh MS. Utility of endobronchial ultrasoundguided transbronchial needle aspiration in diagnosis of intrathoracic lymphadenopathy in patients with human immunodeficiency virus infection. Biomed Res Int 2015;2015:257932.

124. Fujikura Y, Kouzaki Y, Ohta S, Hara Y, Mikita K, Maeda T, et al. A case of Nocardia asteroides infection in a patient with HIV/AIDS diagnosed by endobronchial ultrasound-guided transbronchial needle aspiration (EBUS-TBNA). Intern Med 2012;51(11):1413-1417.

125. Sánchez-Cabral O, Martínez-Mendoza D, Fernandez-Bussy S, Aspuru-García E, Rivera-Rosales R, Luna-Rivero C, et al. Usefulness of Endobronchial Ultrasound in Patients with Human Immunodeficiency Virus Infection and Mediastinal Lymphadenopathy. Respiration 2017;93(6):424-429.

126. Gailey MP, Klutts JS, Jensen CS. Fine-needle aspiration of histoplasmosis in the era of endoscopic ultrasound and endobronchial ultrasound: cytomorphologic features and correlation with clinical laboratory testing. Cancer Cytopathol 2013;121(9):508-517.

127. Egressy Kv, Mohammed M, Ferguson JS. The Use of Endobronchial Ultrasound in the Diagnosis of Subacute Pulmonary Histoplasmosis. Diagn Ther Endosc 2015;2015:510863.

128. Murakami Y, Oki M, Saka H, Kajikawa S, Murakami A, Ishida A. Disseminated cryptococcosis presenting as mediastinal and hilar lymphadenopathy in an immunocompetent patient. Respirol Case Rep 2016;4(4):e00167.

129. Berger J, Zamora F, Podgaetz E, Andrade R, Dincer HE. Usefulness of lymphoid granulomatous inflammation culture obtained by endobronchial ultrasound-guided transbronchial needle aspiration in a fungal endemic area. Endosc Ultrasound 2016;5(4):243-247. 


\section{UltRASONOGRAPHY OF THE MEDIASTINUM}

130. Harris RM, Arnaout R, Koziel H, Folch E, Majid A, Kirby JE. Utility of microbiological testing of thoracic lymph nodes sampled by endobronchial ultrasound-guided transbronchial needle aspiration (EBUS-TBNA) in patients with mediastinal lymphadenopathy. Diagn Microbiol Infect Dis 2016;84(2):170-174.

131. Field AS, Geddie WR. Role of fine needle aspiration biopsy cytology in the diagnosis of infections. Diagn Cytopathol 2016;44(12): 1024-1038.

132. von Bartheld MB, van Breda A, Annema JT. Complication rate of endosonography (endobronchial and endoscopic ultrasound): a systematic review. Respiration 2014;87(4):343-351.

133. Bonta PI, Crombag L, Annema JT. Linear endobronchial and endoesophageal ultrasound: a practice change in thoracic medicine. Curr Opin Pulm Med 2016;22:281-288.

134. Kim SY, Lee JW, Park YS, Lee CH, Lee SM, Yim JJ, et al. Incidence of Fever Following Endobronchial Ultrasound-Guided Transbronchial Needle Aspiration. Tuberc Respir Dis (Seoul) 2017; 80:45-51.

135. Oguri T, Imai N, Imaizumi K, Elshazley M, Hashimoto I, Hashimoto N, Hasegawa Y. Febrile complications after endobronchial ultrasound-guided transbronchial needle aspiration for intra-pulmonary mass lesions of lung cancer-a series of 3 cases. Respir Investig 2012;50(4):162-165

136. Aerts JG, Kloover J, Los J, van der Heijden O, Janssens A, Tournoy KG. EUS-FNA of enlarged necrotic lymph nodes may cause infectious mediastinitis. J Thorac Oncol 2008;3(10):1191-1193.

137. Eapen GA, Shah AM, Lei X, Jimenez CA, Morice RC, Yarmus L, et al; American College of Chest Physicians Quality Improvement Registry, Education, and Evaluation (AQuIRE) Participants. Complications, consequences, and practice patterns of endobronchial ultrasound-guided transbronchial needle aspiration: Results of the AQuIRE registry. Chest 2013;143(4):1044-1053.

138. Vial MR, O'Connell JO, Grosu HB, Ost DE, Eapen GA, Jimenez CA. Needle Fracture during Endobronchial Ultrasound-guided Transbronchial Needle Aspiration. Am J Respir Crit Care Med 2016;193(2):213-214.

139. Asano F, Aoe M, Ohsaki Y, Okada Y, Sasada S, Sato S, et al. Complications associated with endobronchial ultrasound-guided transbronchial needle aspiration: a nationwide survey by the Japan Society for Respiratory Endoscopy. Respir Res 2013;14:50.

140. Yan JH, Pan L, Chen XL, Chen JW, Yan LM, Liu B, Guo YZ. Endobronchial ultrasound versus conventional transbronchial needle aspiration in the diagnosis of mediastinal lymphadenopathy: a meta-analysis. Springerplus 2016;5(1)1716.

141. Çağlayan B, Yılmaz A, Bilaçeroğlu S, Cömert SŞ, Demirci NY, Salepçi B. Complications of Convex-Probe Endobronchial Ultrasound-Guided Transbronchial Needle Aspiration: A Multi-Center Retrospective Study. Respir Care 2016;61(2):243-248.

142. Dhooria S, Sehgal IS, Gupta N, Aggarwal AN, Behera D, Agarwal R. Diagnostic Yield and Complications of EBUS-TBNA Performed
Under Bronchoscopist-directed Conscious Sedation: Single Center Experience of 1004 Subjects. J Bronchology Interv Pulmonol 2017; 24(1):7-14.

143. Bamber J, Cosgrove D, Dietrich CF, Fromageau J, Bojunga J, Calliada $\mathrm{F}$, et al. EFSUMB guidelines and recommendations on the clinical use of ultrasound elastography. Part 1: Basic principles and technology. Ultraschall Med 2013;34(2):169-184.

144. Cosgrove D, Piscaglia F, Bamber J, Bojunga J, Correas JM, Gilja $\mathrm{OH}$, et al; EFSUMB. EFSUMB guidelines and recommendations on the clinical use of ultrasound elastography. Part 2: Clinical applications. Ultraschall Med 2013;34(3):238-253.

145. Nakajima T, Inage T, Sata Y, Morimoto J, Tagawa T, Suzuki H, et al. Elastography for Predicting and Localizing Nodal Metastases during Endobronchial Ultrasound. Respiration 2015;90(6):499-506.

146. Dietrich CF, Jenssen C, Herth FJ. Endobronchial ultrasound elastography. Endosc Ultrasound 2016;5(4):233-238.

147. Giovannini M. Endoscopic ultrasound-guided confocal microscopy: a new tool for the new year? Endosc Ultrasound 2013;2(1):1-2.

148. Giovannini M, Caillol F, Poizat F, Bories E, Pesenti C, Monges G, Raoul JL. Feasibility of Intratumoral Confocal Microscopy under Endoscopic Ultrasound Guidance. Endosc Ultrasound 2012;1(2): 80-83.

149. De Lisi S, Giovannini M. Endoscopic ultrasonography: Transition towards the future of gastro-intestinal diseases. World J Gastroenterol 2016;22(5):1779-1786.

150. Khan F, Anker CJ, Garrison G, Matthew Kinsey CM. Endobronchial ultrasound-guided transbronchial needle injection for local control of recurrent non-small cell lung cancer. Ann Am Thorac Soc 2015;12(1):101-104.

151. Mehta HJ, Begnaud A, Penley AM, Wynne J, Malhotra P, Fernandez-Bussy $\mathrm{S}$, et al. Treatment of isolated mediastinal and hilar recurrence of lung cancer with bronchoscopic endobronchial ultrasound guided intratumoral injection of chemotherapy with cisplatin. Lung Cancer 2015;90(3):542-547.

152. Mehta HJ, Jantz MA. Endobronchial Ultrasound-guided Intratumoral Injection of Cisplatin for the Treatment of Isolated Mediastinal Recurrence of Lung Cancer. J Vis Exp 2017;(120):1-5.

153. Parikh MS, Seeley E, Nguyen-Tran E, Krishna G. Endobronchial Ultrasound-guided Transbronchial Needle Injection of Liposomal Amphotericin B for the Treatment of Symptomatic Aspergilloma. J Bronchology Interv Pulmonol 2017;24(4):330-333.

154. Kirmani B, Kirmani B, Sogliani F. Should asymptomatic bronchogenic cysts in adults be treated conservatively or with surgery? Interact Cardiovasc Thorac Surg 2010;11(5):649-659.

155. Maturu VN, Dhooria S, Agarwal R. Efficacy and Safety of Transbronchial Needle Aspiration in Mediastinal Bronchogenic Cysts Systematic Review of Case Reports. J Bronchology Interv Pulmonol 2015;22(3):195-203. 